\title{
Salient Differences in Tropical Cyclone Activity over the Western North Pacific between 1998 and 2016
}

\author{
RUIFEN ZHAN \\ Shanghai Typhoon Institute of China Meteorological Administration, Shanghai, China, and International \\ Pacific Research Center, and Department of Atmospheric Sciences, School of Ocean and Earth Science \\ and Technology, University of Hawai' $i$ at Mānoa, Honolulu, Hawaii \\ YUQING WANG
}

International Pacific Research Center, and Department of Atmospheric Sciences, School of Ocean and Earth Science and Technology, University of Hawai' $i$ at Mānoa, Honolulu, Hawaii

\section{QINYU LIU}

Physical Oceanography Laboratory/Cooperation and Innovation Center for Marine Science and Technology, Ocean University of China, Qingdao National Laboratory for Marine Science and Technology, Qingdao, China

(Manuscript received 21 April 2017, in final form 21 August 2017)

\begin{abstract}
Previous studies have suggested that tropical cyclone (TC) seasons over the western North Pacific (WNP) in the decaying years of El Niño events are generally less active than normal. The two strongest El Niño events on record were 1997/98 and 2015/16, but TC activities over the WNP displayed a sharp contrast between the decaying years of the two events. In 1998, consistent with previous studies, the WNP witnessed an extremely quiet season with no TC genesis in the preseason (January-June) and with only 10 named TCs observed in the typhoon season (July-October), making 1998 the most inactive season in the basin on record. In 2016, no TC formed in the preseason, similar to 1998; however, the basin became remarkably active in the typhoon season with above-normal named TCs observed. Further analyses indicate that the absence of TCs in the preseason in both 1998 and 2016 and the less active typhoon season in 1998 were attributed to the strong western Pacific anomalous anticyclone associated with the super El Niño events. However, the pattern of sea surface temperature anomalies (SSTAs) in the Pacific in 2016 showed features distinct from that in 1998. During JulyAugust, the extremely positive phase of the Pacific meridional mode (PMM) triggered an anomalous cyclonic circulation and negative vertical wind shear over the WNP, favorable for TC geneses, while during September-October, the combined effect of the equatorial western Pacific warming and the weak La Niña event enhanced TC geneses over the WNP.
\end{abstract}

\section{Introduction}

The western North Pacific (WNP) is the most active basin of tropical cyclone (TC) activity on earth, where about one-third of global TCs form. On average, about 4 TCs (with maximum near-surface wind speed $V_{\max } \geq$ $17 \mathrm{~m} \mathrm{~s}^{-1}$ ) form during January-June (preseason) and about 18 TCs form during July-October (the typhoon season) in the basin. However, the TC activity in 2016 over the WNP experienced an extremely unusual behavior. Although the total annual number of TCs

Corresponding author: Dr. Yuqing Wang, yuqing@hawaii.edu forming in the basin in 2016 was near-average (26), no TC formed over the basin during the preseason, whereas 22 TCs, including 11 intense TCs (ITCs; $V_{\max } \geq$ $41.5 \mathrm{~m} \mathrm{~s}^{-1}$ ), were observed during the typhoon season. The 2016 typhoon season had the third largest numbers of TCs and ITCs since 1990 with the largest contrast of TCs forming in the preseason relative to TCs forming in the typhoon season since 1949 (Fig. 1c). Furthermore, six TCs hit Japan in 2016, the second largest number since 1949. The other absence of TC formation in the preseason over the WNP on record occurred in 1998, in sharp contrast to 2016, in which only 10 TCs formed in the typhoon season, the lowest number since 1949. 

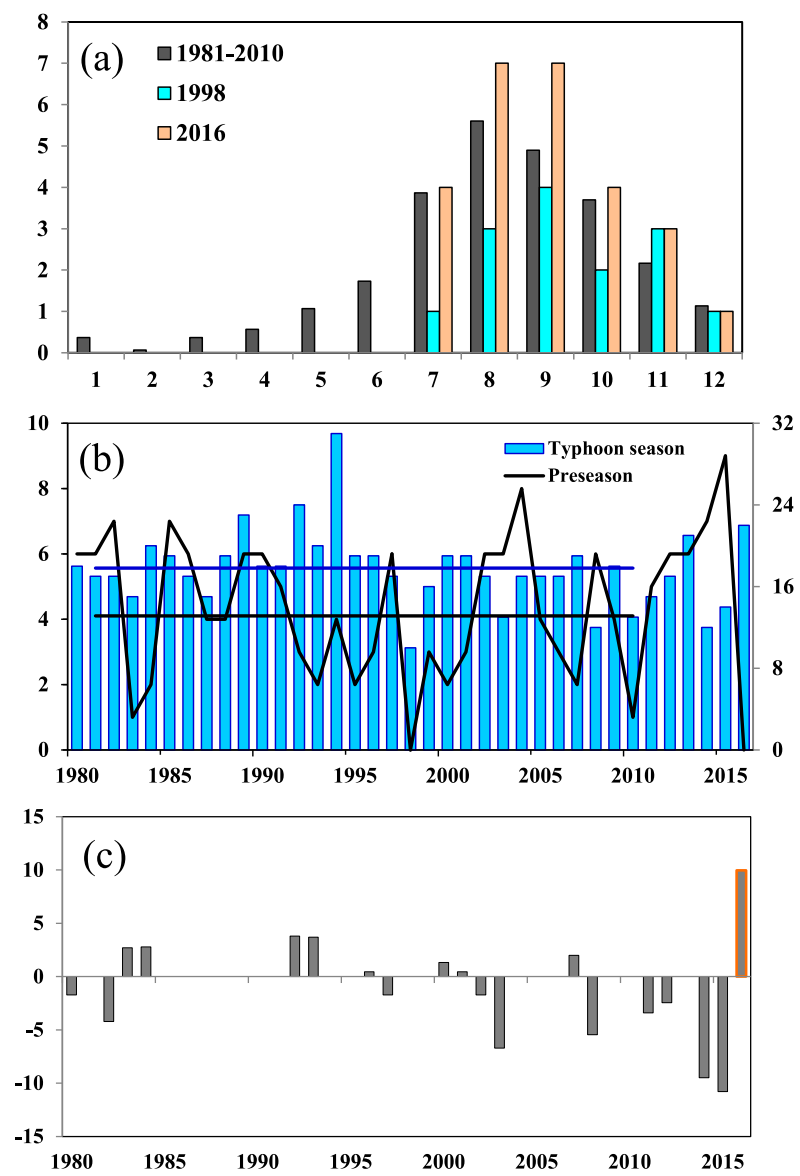

FIG. 1. (a) Monthly tropical cyclone genesis frequency in 1998 (cyan) and 2016 (brown) compared with the 1981-2010 climatological mean (black). (b) Interannual variations of TC genesis frequency during the preseason (black; left ordinate) and the typhoon season (blue; right ordinate) from 1980 to 2016. (c) Interannual variations of TC activity reversal index between January-June and July-December during 1980-2016 as defined in section 2b.

Questions arise as to why no TC formed in the preseason in both 1998 and 2016 and why the difference in TC numbers in the typhoon season between the two years was so dramatic.

Previous studies have shown that TC activity over the WNP is strongly influenced by El Niño-Southern Oscillation (ENSO), the mode dominating the tropical interannual variability. A well-documented effect of ENSO on WNP TC activity is a southeastward (northwestward) shift of the main genesis region of TCs in the developing year of an El Niño (La Niña) event (e.g., Chia and Ropelewski 2002; Wang and Chan 2002; Tao et al. 2012). Since TCs that form in the southeast quadrant in the WNP tend to have a longer time to intensify over the warm tropical ocean, more intense TCs are often observed in El Niño developing years than in La Niña developing years (Camargo and Sobel 2005;
Chen et al. 2006; Chan 2007; Zhan et al. 2011a). More TCs tend to recurve farther north in El Niño developing years, leading to more landfalls over Japan and the Korea Peninsula. On the contrary, more TCs tend to move in a straight line westward or northwestward in $\mathrm{La}$ Niña developing years, resulting in more landfalls over southern China, the Philippines, and Vietnam (Wu et al. 2004; Fudeyasu et al. 2006; Camargo et al. 2007a). However, the correlation between the total annual number of basin-scale TCs over the WNP and the ENSO index is not statistically significant (Lander 1994; Wang and Chan 2002; Zhan et al. 2011a). Nevertheless, many studies have suggested that the typhoon season over the WNP tends to be less active in the decaying year of an El Niño event (Chan 2000; Iizuka and Matsuura 2008; Du et al. 2011; Ha and Zhong. 2013). This is attributed to the anchor of an anomalous anticyclonic circulation (AAC) over the WNP associated with tropical northwest Pacific cooling and tropical Indian Ocean warming [see the review by Xie et al. (2016)].

The two strongest El Niño (hereafter super El Niño) events since the 1950s occurred in 1997/98 and 2015/16 with a sea surface temperature (SST) anomaly (SSTA) in the Niño-3.4 region reaching over $2^{\circ} \mathrm{C}$ in both events. Both 1998 and 2016 were the decaying years of the two super El Niño events. It is thus not surprising that no TC formed over the WNP in the preseason in both 1998 and 2016. It seems that the two extremely inactive preseasons could be well explained by the prolonged effect of the two strongest El Niño events on record. It is also understandable that the typhoon season in 1998 was less active than normal with only 10 named TCs observed over the WNP, making a record of the most inactive year in the basin. However, the extremely active typhoon season in 2016 was in sharp contrast to the inactive typhoon season in 1998. This suggests that although both years were decaying years of super El Niño events, the suppression of TC genesis over the WNP by the AAC was overwhelmed by other effects in 2016.

In addition to the effect of ENSO, TC activity over the WNP is also substantially influenced by SSTAs in the Indian Ocean (Zhan et al. 2011a,b, 2014; Tao et al. 2012), the boreal spring cross-equatorial SST gradient between the southwest Pacific east of Australia and the western Pacific warm pool (Zhan et al. 2013), SSTAs in the tropical western Pacific (Chen and Huang 2008), and SSTAs in the Atlantic (Huo et al. 2015). More recently, Zhang et al. (2016) found that the Pacific meridional mode (PMM) plays an important role in modulating TC activity over the WNP. During the positive PMM phase, which is characterized by positive SSTAs in the northwestern part from the North American coast toward Hawaii and negative SSTAs in the southeastern part in 
the eastern Pacific (Chiang and Vimont 2004), the frequency of TC occurrence over the WNP tends to be higher, and vice versa during the negative PMM phase. Zhang et al. (2017) has introduced the PMM as an important predictor in a statistical-dynamical seasonal forecast model for WNP TCs and shown good performance.

The above discussions suggest that the seasonal TC activity over the WNP could be influenced by SSTAs in various regions with different or coherent spatial patterns. In particular, individual effects could hardly be isolated given the complex nonlinear interactions among SSTAs in different regions. This can be manifested by the saliently different behaviors of TC activity over the WNP in 1998 and 2016 even though both were decaying years of super El Niño events. In fact, several major meteorological services and agencies predicted an inactive TC season over the WNP and fewer TCs making landfall in Japan in 2016 [e.g., the European Centre for Medium-Range Weather Forecasts (ECMWF), Shanghai Typhoon Institute (STI) of the China Meteorological Administration, and Tropical Strom Risk (TSR; available on line at www.tropicalstormrisk.com)]. None of them predicted the abrupt transition from the quiet preseason to the extremely active typhoon season, suggesting that the unusual behavior of TC activity over the WNP in 2016 was an extremely difficult case to be predicted.

The objectives of this study are to document the similarities and differences in TC activity over the WNP and the evolution of SSTAs in different regions in 1998 and 2016, with a focus on understanding the mechanisms by which the large-scale circulation over the WNP responds to various SSTAs and results in the contrasting behaviors of TC activities in the two typhoon seasons. The remainder of the paper is organized as follows. Section 2 describes the data used and analysis methods. TC activities in 1998 and 2016 are examined and compared in section 3. Section 4 investigates the possible mechanisms that caused the salient differences in TC activities between 1998 and 2016. Finally, the main conclusions and a discussion are provided in section 5 .

\section{Data and methods}

\section{a. Data}

The TC best-track data used in this study were obtained from the Shanghai Typhoon Institute of the China Meteorological Administration (CMA; Ying et al. 2014) for the period 1980-2016. TCs referred in this study are systems with at least tropical storm (TS) intensity (with maximum sustained $10-\mathrm{m}$ wind speed $V_{\max } \geq 17 \mathrm{~m} \mathrm{~s}^{-1}$ ) between $100^{\circ} \mathrm{E}$ and $180^{\circ}$ over the WNP including the South China Sea (SCS). We also used the monthly extended reconstructed SST (ERSST.v4) analyses from the National Oceanic and Atmospheric Administration (NOAA; Smith and Reynolds 2004) and monthly atmospheric data from the National Centers for Environmental Prediction (NCEP)-National Center for Atmospheric Research (NCAR) reanalysis data (Kalnay et al. 1996). In addition, the monthly Climate Prediction Center (CPC) Merged Analysis of Precipitation (CMAP; Xie and Arkin 1997) and the monthly seawater temperature from the NCEP Global Ocean Assimilation System (GODAS) reanalysis data (Ji et al. 1995) were utilized.

\section{b. Methods}

There are various measures of TC activity. In this study, we examined TC genesis number, TC track, the TC day defined as the accumulated duration of all TC records (Emanuel 2005), intense TC (ITC; $V_{\max } \geq 41.5 \mathrm{~m} \mathrm{~s}^{-1}$ ) number, and the accumulated cyclone energy (ACE) defined as the sum of the square of $V_{\max }$ at 6-hourly intervals for all TCs each year (Bell et al. 2000). We defined the period January-June as the preseason and the period July-October as the typhoon season. Note that TC activity in the period November-December was not examined in this study because TC genesis numbers in the same period of 1998 and 2016 were the same and close to normal (4 vs 3.5) as shown in Fig. 1a.

The Niño-3.4 index (SSTA averaged in the area of $5^{\circ} \mathrm{S}-5^{\circ} \mathrm{N}, 120^{\circ}-170^{\circ} \mathrm{W}$ ) was extracted from the ERSST.v4 analyses. The PMM index was calculated following the method described in Chiang and Vimont (2004) and downloaded from the website https://www.esrl.noaa.gov/ psd/data/timeseries/monthly/PMM. The AAC index was defined as the $850-\mathrm{hPa}$ zonal wind difference in two regions - the average over $20^{\circ}-30^{\circ} \mathrm{N}, 100^{\circ}-140^{\circ} \mathrm{E}$ minus that in $5^{\circ}-15^{\circ} \mathrm{N}, 90^{\circ}-130^{\circ} \mathrm{E}$ over the WNP based on the NCEP-NCAR reanalysis data (Fan et al. 2013). The vertical wind shear (VWS) was defined as the difference of vector winds between 200 and $850 \mathrm{hPa}$. All anomalies used in this study are relevant to the climatological mean in the base period of 1981-2010.

To quantify the transition of TC activity from the preseason to the typhoon season, a reverse index (RI) was defined as

$$
\begin{aligned}
\mathrm{RI} & =P \times\left(F_{2}-F_{1}\right) \times\left(\left|F_{1}\right|+\left|F_{2}\right|\right) \quad \text { and } \\
P & = \begin{cases}0, & F_{1} \times F_{2}>0 \\
1, & F_{1} \times F_{2}<0\end{cases}
\end{aligned}
$$

where $F_{1}$ and $F_{2}$ are the normalized TC genesis frequency during the preseason and the typhoon season, respectively, and $P$ is the step function that defines whether a reversal of TC activity occurs $(=1)$ or not $(=0)$. 
TABLE 1. Numbers of all TCs and ITCs, TC days, and ACE in 1998 and 2016, and their corresponding averages in the 8 El Niño decaying (END) years (1983, 1988, 1992, 1998, 2003, 2005, 2010, and 2016) and averages in the 30-yr climatological period during 1981-2010, respectively. The values in parentheses indicate the corresponding standard deviations.

\begin{tabular}{|c|c|c|c|c|c|}
\hline & & 1998 & 2016 & END years & 1981-2010 \\
\hline \multirow[t]{2}{*}{ TC frequency } & Annual & 14 & 26 & 22.1 & $25.5(4.7)$ \\
\hline & JASO & 10 & 22 & 16.6 & $17.8(3.8)$ \\
\hline \multirow[t]{2}{*}{ Intense TC frequency } & Annual & 3 & 13 & 8.5 & $9.0(3.3)$ \\
\hline & JASO & 3 & 11 & 6.8 & $6.4(2.5)$ \\
\hline \multirow[t]{2}{*}{ TC day } & Annual & 64 & 134 & 124.9 & $152(40)$ \\
\hline & JASO & 56 & 115 & 94.0 & $108(29)$ \\
\hline \multirow[t]{2}{*}{ ACE } & Annual & 23.1 & 52.5 & 50.8 & $60.3(20.0)$ \\
\hline & JASO & 21.5 & 49.7 & 38.9 & $43.4(14.3)$ \\
\hline
\end{tabular}

The value of $F_{2}-F_{1}$ reflects the reversing intensity. The larger $F_{2}-F_{1}$ is, the greater the reversal is, and vice versa. The quantity $\left|F_{2}\right|+\left|F_{1}\right|$ is the weighting coefficient that magnifies the anomalies of TC activity.

\section{An overview of TC activities in 1998 and 2016}

Figure 1a shows monthly TC genesis frequency in 1998 and 2016 compared with the 1981-2010 climatological mean. As mentioned in section 1, no TC was observed over the WNP in the preseason in both 1998 and 2016, the only two years since 1980 (Fig. 1b). TC activity remained rather less active than normal in the whole typhoon season in 1998, with the largest anomaly in August (-2.7), whereas it was above normal through the whole typhoon season in 2016, with the largest anomaly in September (2.2). As a result, the TC genesis frequency in the 1998 typhoon season had a record low value (10) in the WNP, while the 2016 typhoon season with 22 TCs became the fourth most active typhoon season since 1980 (Fig. 1b). During NovemberDecember, four TCs formed in both 1998 and 2016, close to the climatological mean.

Figure $1 \mathrm{c}$ presents the interannual variation of the reversal index of TC genesis frequency (see section $2 b$ ) during 1980-2016. The positive (negative) value reflects the reversal from inactive (active) season to active (inactive) season. The TC genesis frequency experienced the largest positive reversal in 2016 and the largest negative reversal in 2015. Such a big positive reversal in TC genesis is very rare climatologically, implying little predictability. It is not surprising that major agencies issuing seasonal forecasts for WNP TCs (e.g., TSR, ECMWF, and STI) failed to predict the extremely active typhoon season in 2016, as mentioned in introduction.

Table 1 compares several other main metrics for TC activities in 1998 and 2016 typhoon seasons as well as in the whole years, including numbers of all TCs and ITCs, number of TC days, and ACE. The corresponding metrics averaged for the decaying years of all El Niño events during 1980-2016 and averaged for the 30-yr climatological period during 1981-2010, respectively, are also given for comparisons. Here an El Niño year is defined according to the normalized time series of the Niño-3.4 index with SSTA $\geq 0.5$ standard deviation averaged in the typhoon season during 1980-2016. As a result, 1982, 1987, 1991, 1997, 2002, 2004, 2009, and 2015 were El Niño years, and correspondingly, 1983, 1988, 1992, 1998, 2003, 2005, 2010, and 2016 were El Niño decaying years. Consistent with previous studies (Chan 2000; Du et al. 2011), most of the metrics averaged in the eight El Niño decaying years were below normal except for the frequency of ITCs, which was close to their climatological means. However, all of the anomalies were less than their corresponding standard deviations (see Table 1).

For 1998, all TC metrics regardless in the whole year or the typhoon season were dramatically lower than either their averages in the eight El Niño decaying years or their climatological means, with the corresponding anomalies greater than one standard deviation. For 2016, all TC metrics were considerably higher than their averages in the eight El Niño decaying years. Note also that most of the metrics were even higher than their corresponding climatological means except for the TC days and the annual ACE. In particular, the TC frequency in the typhoon season and ITC frequencies in both the whole year and the typhoon season were significantly above normal, with their corresponding anomalies larger than one standard deviation. This suggests that the annual mean lifespan of TCs in 2016 could be shorter than the long-term mean, mainly because of the northward shift of the mean TC genesis location (see discussion below). All these characteristics in 2016 differed greatly from those in 1998, indicating that TC activities in the decaying years of super El Niño events could be quite complicated.

Figure 2 shows TC genesis positions (green circles) and tracks (red curves) in the 1998 and 2016 typhoon seasons, and the anomalies of seasonal TC genesis and 

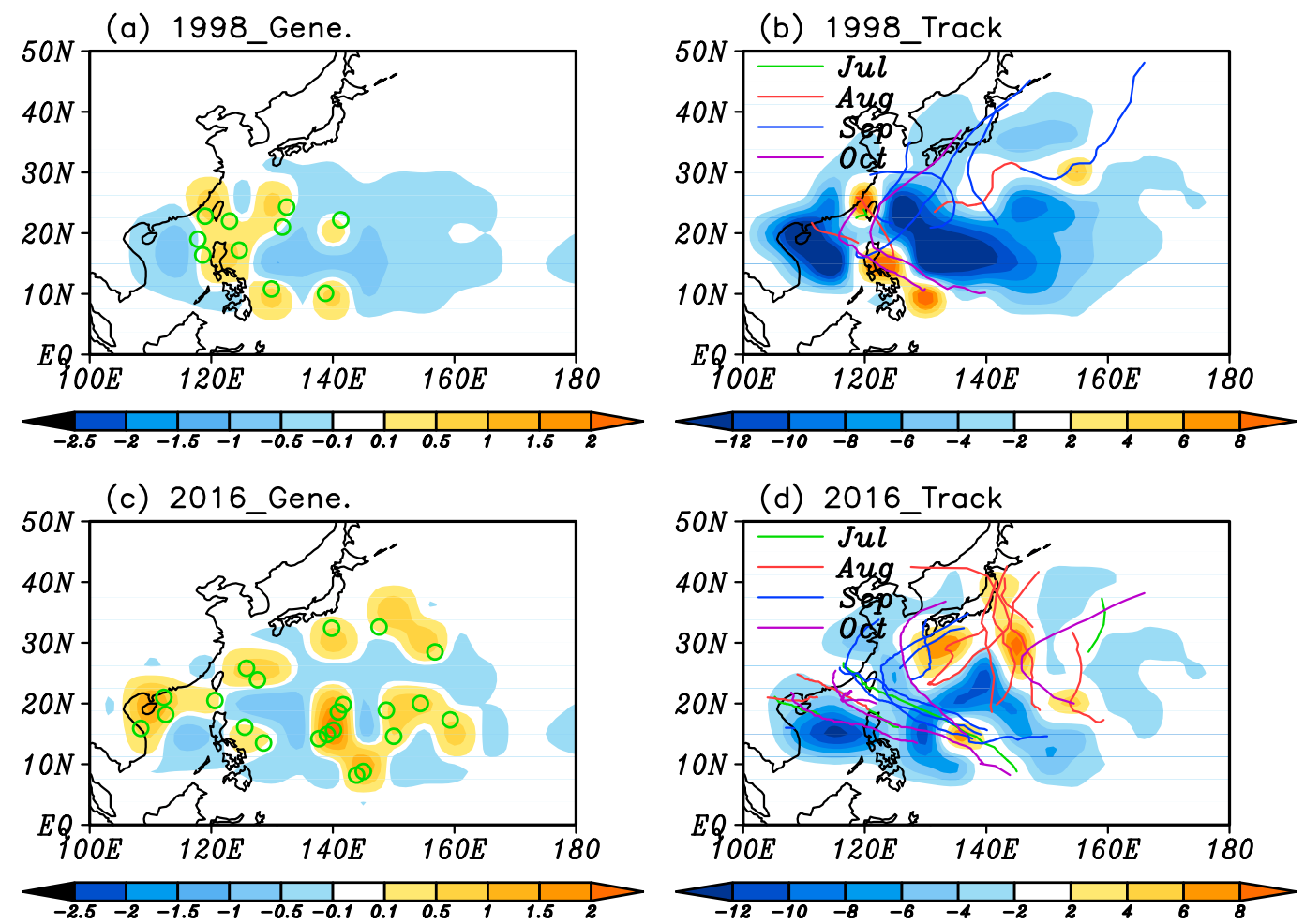

FIG. 2. (a),(c) TC genesis frequency and (b),(d) occurrence frequency anomalies (units for both are counts per year) in each $5^{\circ} \times 5^{\circ}$ grid box in (top) 1998 and (bottom) 2016. The value in each grid box is the sum of all detected TCs within a $5^{\circ} \times 5^{\circ}$ grid box. The green circles in (a) and (c) indicate TC genesis positions, and the curves in (b) and (d) indicate tracks in 1998 and 2016, respectively.

occurrence frequencies relative to their climatological means. Here, the frequencies were calculated within a $5^{\circ} \times 5^{\circ}$ longitude-latitude box by counting the numbers of TC genesis and their occurrence, and the TC genesis position indicates the first point where the $\mathrm{TC}$ reached TS intensity. Since no TC formed during the preseasons of both years, Fig. 2 reflects TC activity in the typhoon season. In 1998 , TCs formed mainly west of $140^{\circ} \mathrm{E}$ over the western WNP (Fig. 2a) and tended to recurve from northwestward to northeastward (Fig. 2b), resulting in more landfalls in coastal regions of eastern China and a higher ratio $(30 \%)$ of TCs making landfall in Japan to total TCs than the climatology (around 11\%). In sharp contrast, although TC genesis occurred in the whole WNP in 2016, the mean TC genesis location shifted northward by about $4^{\circ}$ latitude, greater than one standard deviation. Moreover, six TCs took the northward and northeastward tracks and made landfall in Japan, more than twice of the climatological mean $(2.7 \mathrm{TCs})$. Most of them occurred in August and September.

These large differences in TC activities between 1998 and 2016 suggest a complex and changing relationship between TC activity and the decaying years of super El Niño events. Therefore, it is necessary to explore the possible mechanisms responsible for the saliently different behaviors in TC activity in these two years. Since TC activity in 2016 experienced a remarkable reversal from the preseason to the typhoon season, we first compare SSTAs and the large-scale circulation anomalies in the two seasons in 1998 and 2016, and then discuss contributions of various SSTA patterns to the salient differences in the next section.

\section{Possible mechanisms}

\section{a. SSTAs and large-scale circulation anomalies}

Figure 3 shows the monthly mean SST and $850-\mathrm{hPa}$ wind anomalies from January to June in 1998 and 2016, respectively. The most prominent feature in these two years is an enormously strong positive SSTA in the equatorial central and eastern Pacific (ECEP), showing the super El Niño signal. This SSTA was strongest in January and gradually decayed with time. Another important feature is a basinwide warming in the tropical Indian Ocean. These SSTA distributions were responsible for the anomalous equatorial easterlies west of $180^{\circ}$ and an AAC over the WNP (Du et al. 2011; Zhan 

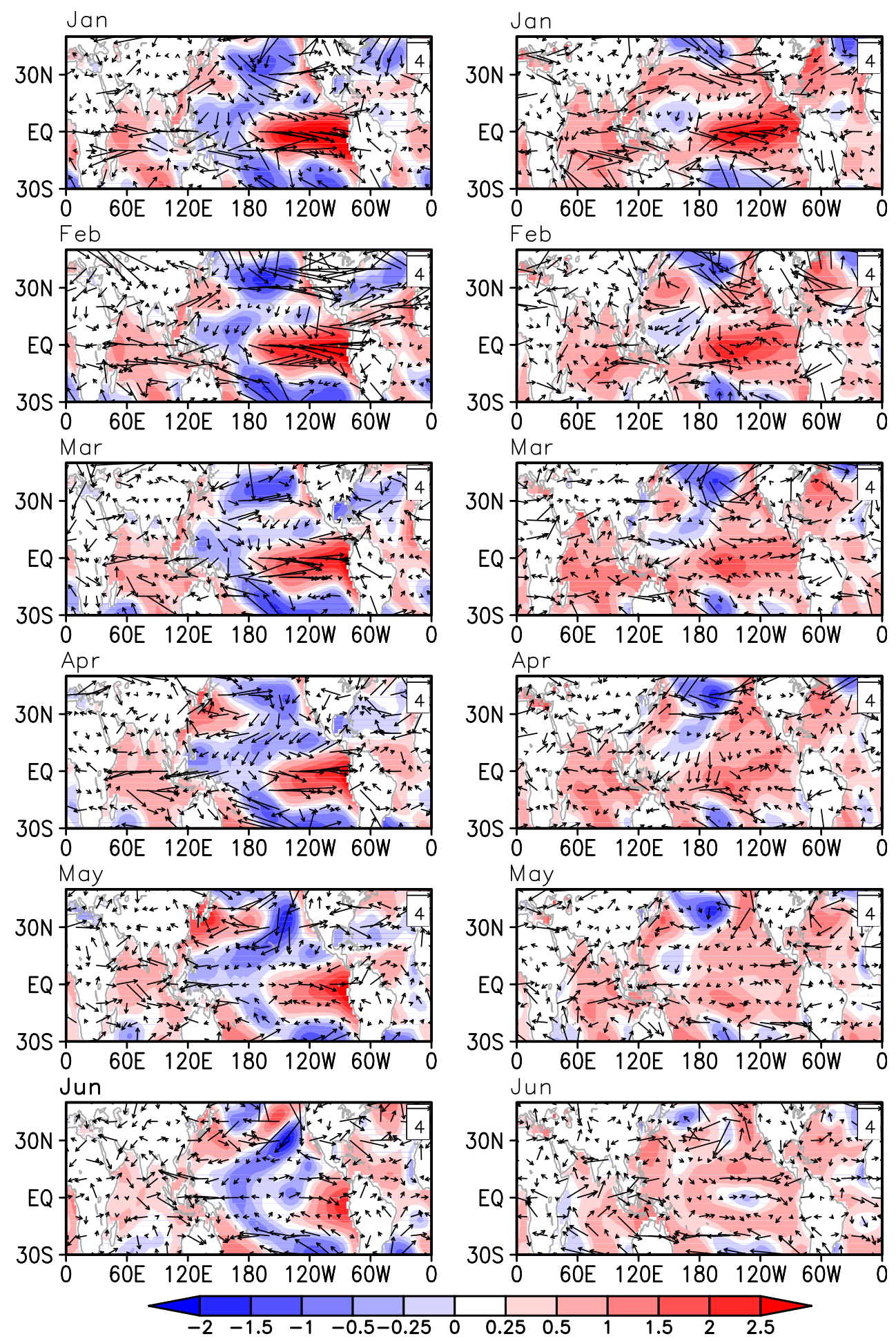

FIG. 3. Monthly mean SSTA (color shaded; ${ }^{\circ} \mathrm{C}$ ) and $850-\mathrm{hPa}$ wind (vectors; $\mathrm{m} \mathrm{s}^{-1}$ ) anomalies (top)(bottom) from January to June in (left) 1998 and (right) 2016. The legend at the upper-right corner of the figure indicates a reference vector magnitude. 

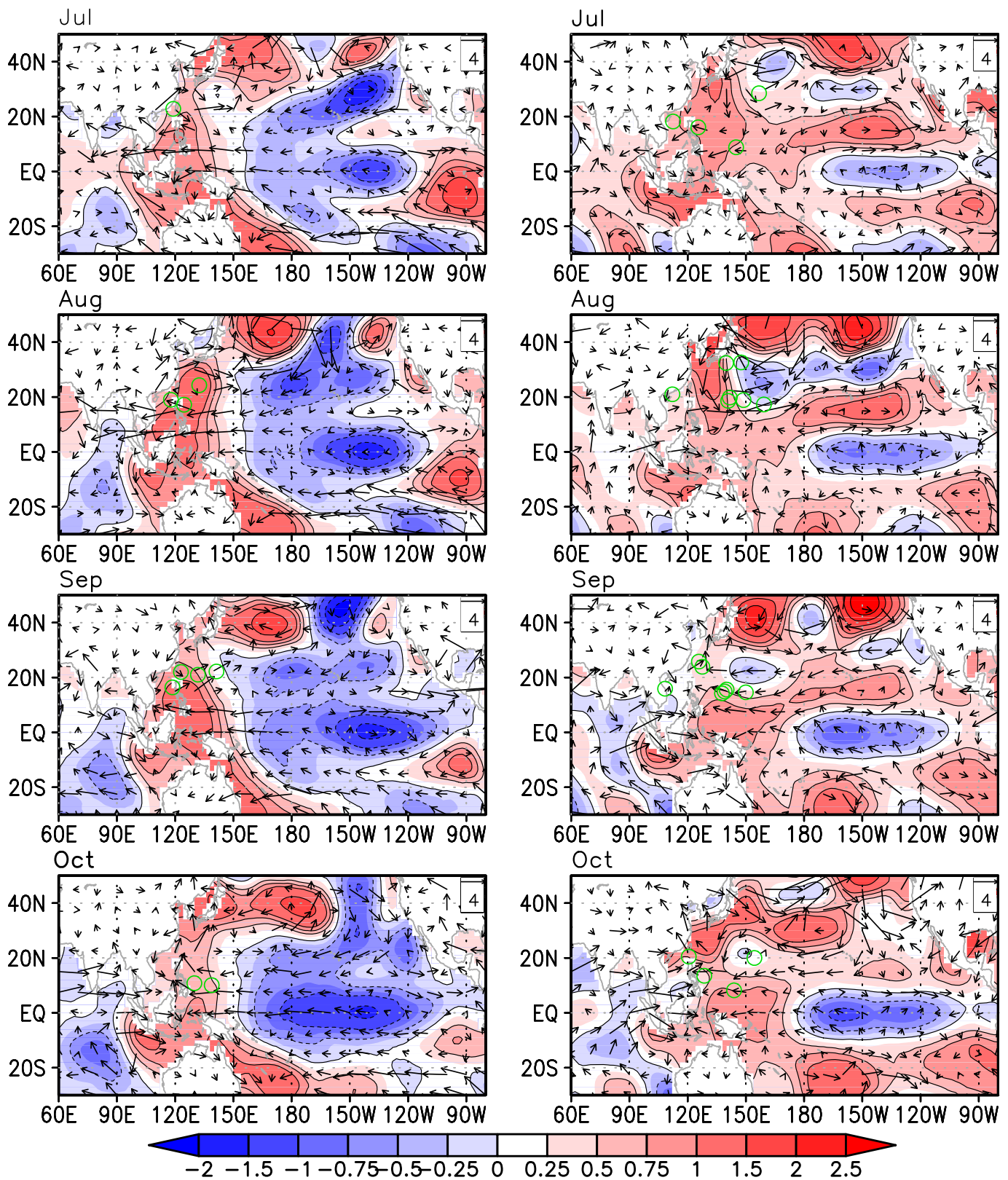

FIG. 4. As in Fig. 3, but from July to October. The green circles indicate TC genesis positions. The legend at the upper-right corner of the figure indicates a reference vector magnitude.

et al. 2011a,b; Xie et al. 2016). Consequently, the development and maintenance of the AAC contributed largely to the extremely quiet preseasons over the WNP in both 1998 and 2016, consistent with previous studies found for the decaying years of historical strong El Niño events (Chan 2000; Du et al. 2011).

Although evolutions of SSTAs in the Indian Ocean and the ECEP were similar in the 1998 and 2016 preseasons, the SSTA distribution in the outer ring of the ECEP exhibited a remarkable difference (Fig. 3). In the 1998 preseason, slanting "L shaped" negative SSTAs appeared in the outer ring of the positive SSTAs over the ECEP, showing a spatial pattern similar to the mega ENSO defined by Wang et al. (2013). Such a distribution persisted and intensified through the following typhoon season (Fig. 4) and helped maintain the AAC by local air-sea feedbacks (Wang et al. 2003). On the other hand, the positive SSTA in the tropical Indian Ocean, especially in the southeastern part, and negative SSTAs in the local WNP and the central tropical Pacific also played important roles in the maintenance of a strong AAC in the WNP in the 1998 summer (Yang et al. 2007; 
Wu et al. 2010; Wu et al. 2012; Fan et al. 2013; Chen et al. 2016). As a result, the persistence of the strong AAC reduced TC geneses over the WNP from the preseason to the typhoon season in 1998. In sharp contrast, the mega-ENSO-like SSTA pattern was not obvious in 2016. Instead, a positive SSTA appeared in the subtropical eastern Pacific and a considerably weak negative SSTA occurred in the tropical WNP. In June of 2016, the weak negative SSTA in the tropical WNP even turned to positive SSTAs. This difference led to a much weaker AAC over the western WNP in the spring of 2016 than in the spring of 1998 (Fig. 3).

Figure 4 shows the monthly mean SST and $850-\mathrm{hPa}$ wind anomalies from July to October in 1998 and 2016, respectively. During July-August of 2016, the positive SSTA in the subtropical eastern Pacific tended to further intensify. Following the development of a weak La Niña event, SSTAs in the central and eastern Pacific exhibited a typical pattern of the positive PMM phase, with positive SSTAs in the northwestern part and negative SSTAs in the southeastern part of the eastern Pacific (Chiang and Vimont 2004). This positive PMM phase offset the AAC by triggering an anomalous cyclonic circulation over the WNP TC genesis region (Zhang et al. 2016), favorable for TC genesis. This was consistent with the fact that most of TCs formed within the anomalous cyclonic circulation in this period, as shown in green circles in Fig. 4 (July-August in the right column). Note that July is a transition month from the AAC to the anomalous cyclone over the WNP, in which all TCs formed during late July (23, 26, and 30 July) except for one that formed on 3 July in the region of lowlevel anomalous easterly winds near the equator $\left(8.8^{\circ} \mathrm{N}\right.$, $\left.145^{\circ} \mathrm{E}\right)$. Because of the use of monthly data in our analysis, such a transition could not be displayed well, making the anomalous cyclonic circulation over the WNP somewhat weak and narrow in Fig. 4 (see the panel for July in the right column). In fact, TCs formed within or near the edge of the anomalous cyclone in late July 2016 (not shown). Note also that active TCs led to the local cooling in the WNP in August 2016 and the positive PMM rapidly weakened during September-October. As a result, the strong anomalous cyclone over the WNP in August 2016 disappeared in September. This suggests that the role of the PMM was not significant from September 2016.

The SSTA fields in Fig. 4 also suggest remarkable differences in the development of the La Niña event and the warming pattern in the tropical western Pacific and east Indian Ocean between the 1998 and 2016 typhoon seasons. From July to October, cold SSTAs associated with the developing La Niña event continuously amplified in the ECEP and extended westward in both years.
However, cold SSTAs extended westward to west of $150^{\circ} \mathrm{E}$ and covered a large area with an increasing magnitude through October in 1998, suggesting a strong La Niña event, whereas the westward extension of cold SSTAs in 2016 stopped near the date line, with the magnitude slightly increasing through October, suggesting a weak La Niña event. On the other hand, similar to the usual decaying year of a strong El Niño event, large warming developed and intensified over the east Indian Ocean and the SCS and peaked in August and September in 1998 (Du et al. 2011). Similar warming occurred in 2016 but the warming appeared in the tropical western Pacific between $120^{\circ}$ and $160^{\circ} \mathrm{E}$ in the TC genesis region over the WNP. In response to the SSTA patterns, the anomalous easterlies in the lower troposphere associated with the strong La Niña event in 1998 prevailed from the equatorial central Pacific to the SCS in the typhoon season, unfavorable for TC genesis over the WNP. TCs mainly formed in the anomalous cyclonic circulation northwest of the WNP. On the contrary, in the 2016 typhoon season, the anomalous equatorial easterlies associated with the weak La Niña event were very weak and only extended to about $135^{\circ} \mathrm{E}$ with the anomalous westerlies prevailing to the west (Fig. 4). This was favorable for the anomalous low-level confluence (figure not shown) and led to an anomalous low-level confluence zone slightly east of the Philippines (Fig. 4). This low-level wind pattern tended to enhance the monsoon confluence zone west of around $140^{\circ} \mathrm{E}$ and helped trigger the successive developments of TCs over the WNP (dots in Fig. 4), although the monsoon trough slightly shifted westward. This low-level wind pattern also acted to pile up warm water in the upper ocean mixed layer, thus leading to the prominent warming in the tropical western Pacific from July through October in 2016. The latter in turn could further enhance TC genesis in the northwestern WNP (Chen and Huang 2008).

The above analyses strongly suggest that ENSO, the AAC, the PMM, the anomalous low-level confluence zone, and the western Pacific warming behaved differently between the 1998 and 2016 typhoon seasons. To further quantify their different evolutions and relative contributions in the two years, we show in Fig. 5 the monthly evolutions of Niño-3.4 index, PMM index, AAC index, and the tropical zonal wind (TU) index averaged in the area of $0^{\circ}-10^{\circ} \mathrm{N}, 100^{\circ}-120^{\circ} \mathrm{E}$ from January to October. Here the TU index was defined to measure the strength of the anomalous low-level westerlies that met the anomalous low-level easterlies in the anomalous confluence zone as mentioned above. We can see that the positive SSTA in the Niño-3.4 region dissipated since June and then transitioned rapidly to 
(a) Nino3.4

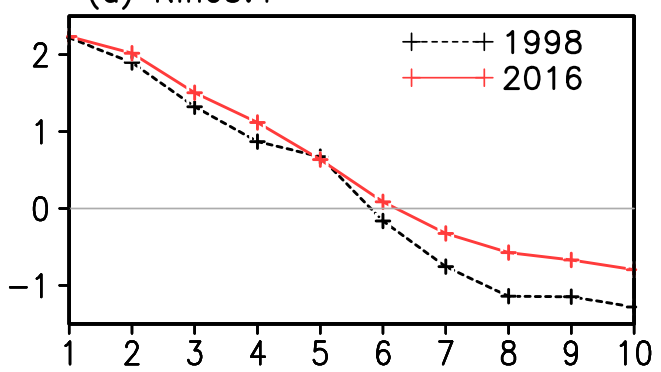

(c) AAC

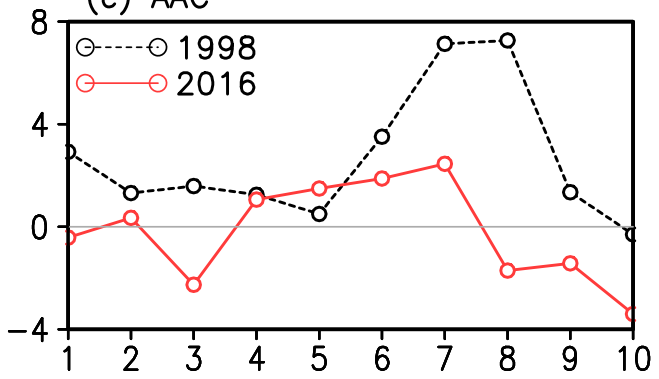

(b) PMM

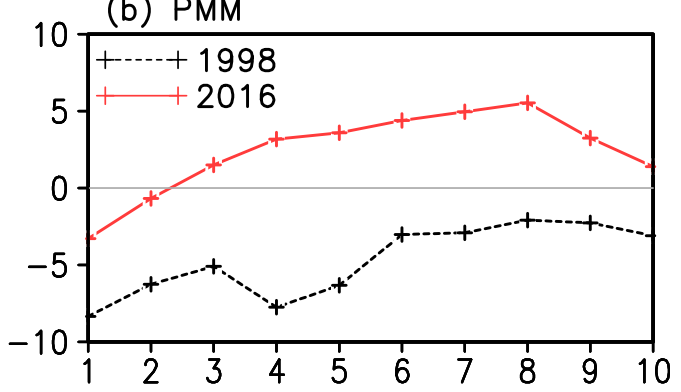

(d) TU

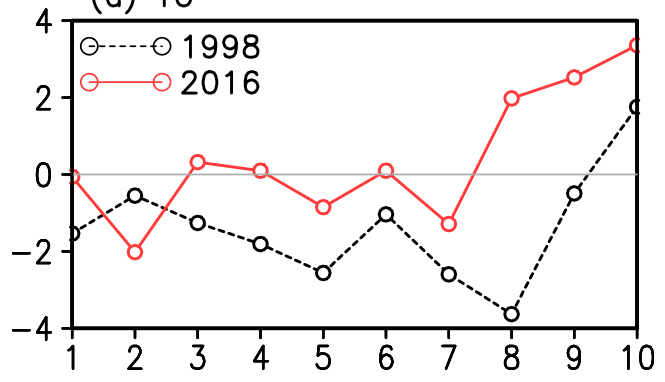

FIG. 5. Evolutions of the monthly mean (a) Niño-3.4 index, (b) PMM index, (c) AAC, and (d) TU index from January to October in 1998 (dashed black) and 2016 (solid red). All of the indices are anomalies from their climatological means.

negative anomalies in both 1998 and 2016 (Fig. 5a). Compared with 1998, the negative Niño-3.4 index in 2016 was smaller, suggesting a weaker La Niña event in 2016. In sharp contrast, the PMM index in 2016 was much higher than that in 1998 (Fig. 5b). It turned to be positive and increased from March, peaked in August, and weakened afterward, suggesting that the PMM might contribute to active WNP TC activity during JulyAugust in 2016. Accordingly, the AAC index was much weaker in 2016 than in 1998 and even became negative from August (Fig. 5c), whereas the AAC reached a high level in the boreal summer of 1998. The TU index was generally negative (Fig. 5d) in 1998, which was associated with the westward penetration of the strong tropical easterly anomalies induced by the strong La Niña event. However, high positive TU index appeared during August-October and peaked in October in 2016.

These results suggest that the early active typhoon season in July and August in 2016 was most likely controlled largely by the PMM pattern and the late active typhoon season in September-October of 2016 might be modulated by a combination of the tropical western Pacific warming and the weak La Niña event. In the following discussion, we will examine the two periods separately to further our understanding of the dynamical and thermodynamic processes that contributed to the sharp differences in TC activities between 1998 and 2016.

\section{b. Influence of PMM during July-August}

Figures 6 and 7 show seasonal mean 200-hPa divergent wind and velocity potential anomalies and seasonal mean precipitation and $850-\mathrm{hPa}$ wind anomalies for May-July (MJJ) and June-August (JJA) in 1998 and 2016, respectively. Here we used the 3-month mean to reduce the influence of TCs on the local thermodynamic and dynamical fields. In 1998, the upper troposphere was featured by a strong and wide convergence region extending from $120^{\circ} \mathrm{E}$ to $120^{\circ} \mathrm{W}$, while the uppertropospheric divergence and anomalous precipitation over the eastern Pacific were weak and located in a narrow region. In contrast, in 2016, the wide and strong upper-level divergence and anomalous precipitation appeared over the eastern Pacific and shifted westward, implying anomalous convection and ascending motion therein. The anomalous convective heating helped trigger an anomalous cyclonic circulation to its northwest in the lower troposphere as a Gill-type Rossby wave response (Gill 1980) and extended westward to the WNP in JJA, favoring TC genesis. This is consistent with the atmospheric response to the positive PMM phase as discussed in Zhang et al. (2016). Note that the anomalous cyclone over the WNP shifted westward from MJJ to JJA, most likely due to the decaying and disappearing of the AAC. Previous studies have shown that the AAC is closely related to the positive SSTA in the tropical 

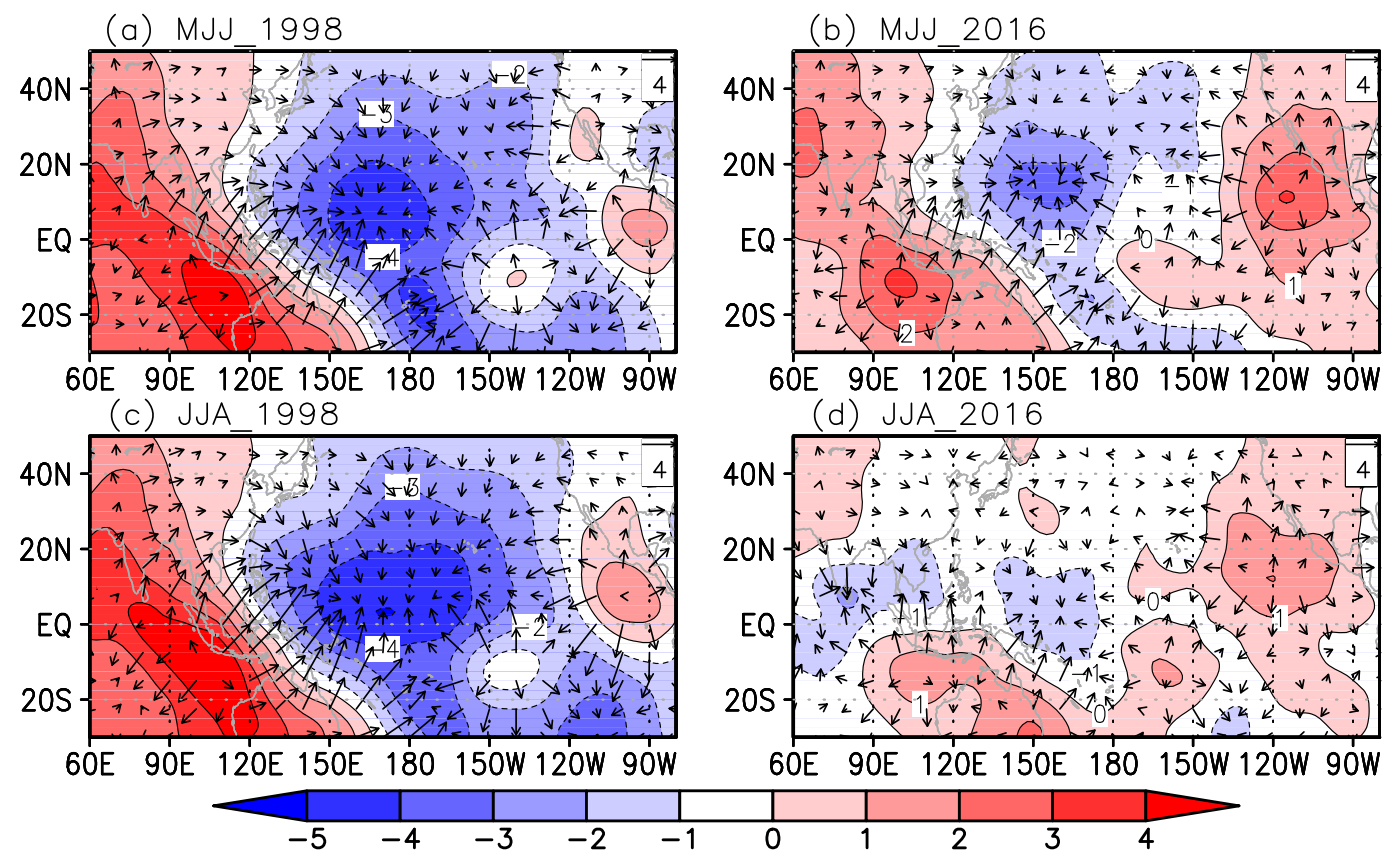

FIG. 6. Seasonal mean 200-hPa divergent wind (vectors) and velocity potential (color shaded; $10^{6} \mathrm{~m}^{2} \mathrm{~s}^{-1}$ ) anomalies for the (a),(b) MJJ and (c),(d) JJA mean in (left) 1998 and (right) 2016. The legend at the upper-right corner of the figure indicates a reference vector magnitude.

Indian Ocean and negative SSTAs in the local WNP and the central tropical Pacific (Yang et al. 2007; Xie et al. 2009; Wu et al. 2010; Fan et al. 2013). After June 2016, the tropical Indian Ocean warming weakened and local WNP cooling disappeared, and thus in response the
AAC decayed and disappeared. At the same time, the positive PMM became stronger and even offset the AAC. As a result, the anomalous cyclone induced by the PMM shifted westward, favorable for TC genesis over the WNP. (a) MJJ 1998

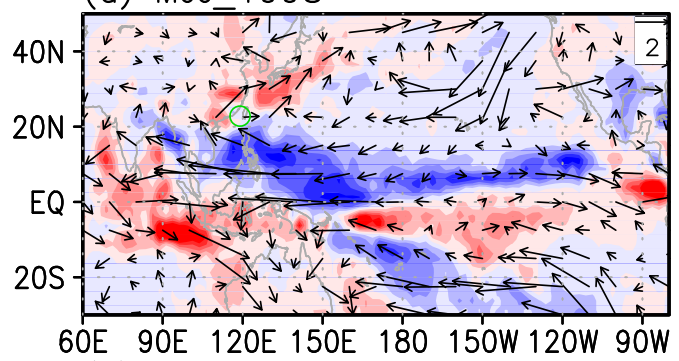

(c) JJA 1998

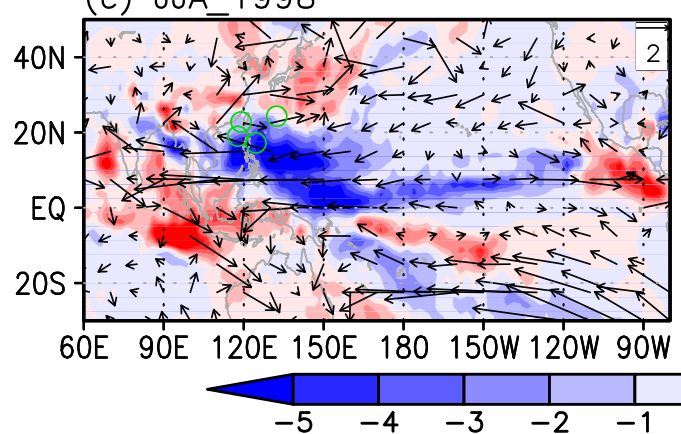

(b) MJJ 2016

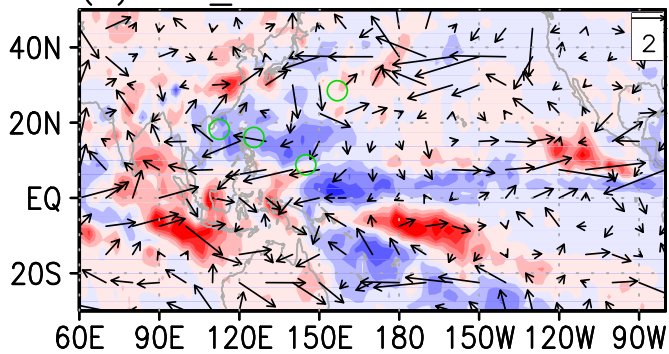

(d) JJA_2016

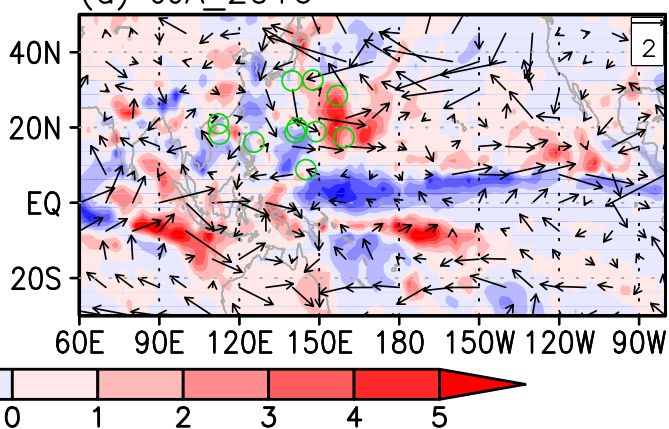

FIG. 7. As in Fig. 6, but for precipitation (color shaded; $\mathrm{mm}$ ) and 850 -hPa wind (vectors; $\mathrm{m} \mathrm{s}^{-1}$ ) anomalies. 
We calculated the correlation between the PMM index and WNP TC genesis frequency in July-August during 1980-2015. The correlation coefficient reached 0.40 , which is statistically significant well above $95 \%$ confidence level. This suggests that the July-August positive PMM phase indeed tends to enhance TC genesis over the WNP. We further composited the atmospheric fields between the positive and negative PMM years. The positive (negative) PMM years were selected if the PMM index averaged in July-August in a year was larger (less) than $80 \%(-80 \%)$ of its standard deviation. Based on this criterion, five positive PMM years (1985, 1986, 1990, 1992, and 1994) and six negative PMM years (1983, 1997, 1999, 2008, 2011, and 2012) were defined. Figure 8 presents the composite differences in $850-\mathrm{hPa}$ winds, VWS, and 500-hPa geopotential height between the mean positive and mean negative PMM years.

In the positive PMM phase, an anomalous cyclonic circulation occupied a region from the SCS to around $160^{\circ} \mathrm{E}$ over most of the WNP (Fig. 8a), and a significantly negative VWS anomaly occurred over the western WNP and a positive but insignificant VWS anomaly over the southern NWP (Fig. 8b). Negative anomalies in 500-hPa geopotential height appeared over most of the WNP with a north-south-oriented negative region between $140^{\circ}$ and $150^{\circ} \mathrm{E}$ (Fig. 8c). The latter helped split the WNP subtropical high into two parts (not shown) and resulted in more landfalling TCs in Japan. These patterns associated with the positive PMM phase were favorable for TC genesis over the WNP. These are all consistent with the circulation anomalies in 2016 shown in Figs. 4 and 7 and the results of Zhang et al. (2016) based on the typhoon season, and thus contributed to the active TC activity during July-August in 2016. Actually, the JulyAugust mean PMM index in 2016 reached as high as 1.63, the second highest value during 1980-2016, with the highest (1.68) in 1994 in which the largest number of TCs on record formed. Note that the location of the anomalous cyclonic circulation in July-August 2016 was slightly different from that of the composite difference in the low-level circulation shown in Fig. 8a. The former shifted northward compared to the latter, which might be associated with the asymmetric atmospheric responses to the positive and negative PMM phases. The composite 850-hPa horizontal wind anomalies averaged in July-August in the positive and negative PMM phases showed an anomalous cyclonic circulation widely from the SCS to around $160^{\circ} \mathrm{E}$ over most of the WNP in the positive phase of PMM years but an anomalous anticyclone in the southeast quadrant of the WNP and an anomalous cyclone in the northwest quadrant in the negative PMM phase (figures not shown). It is the dipole pattern in the negative PMM phase that led to the
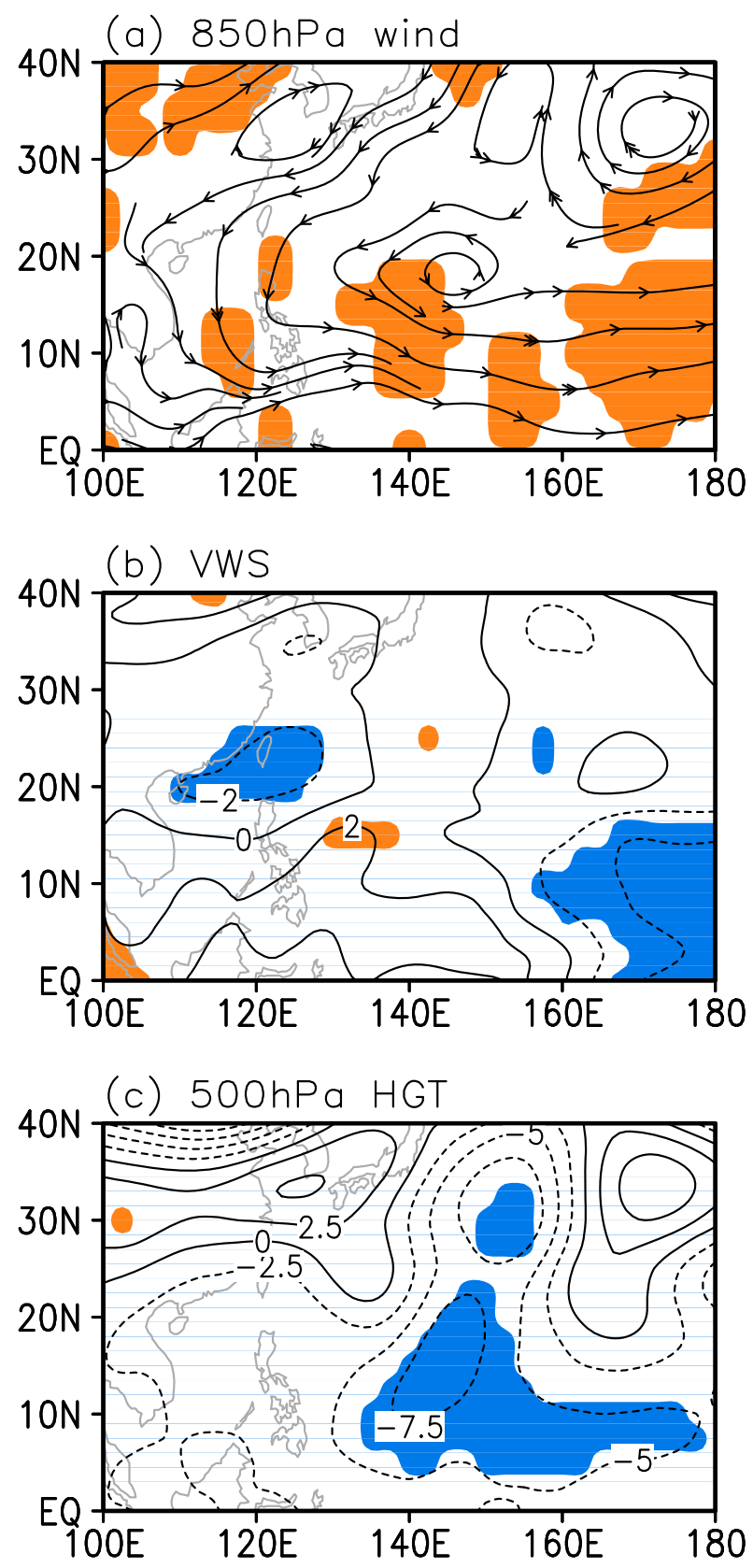

FIG. 8. Composite differences in (a) 850-hPa horizontal wind (streamlines), (b) vertical wind shear (VWS; $\mathrm{m} \mathrm{s}^{-1}$ ), and (c) 500-hPa geopotential height (HGT; gpm) averaged in July-August between the positive and negative phase of PMM years. Shading in (a) indicate areas where the difference in vector winds is statistically significant at the $95 \%$ confidence level by the Student's $t$ test. Orange (blue) shades in (b) and (c) indicate areas where the positive (negative) difference is statistically significant at the $95 \%$ confidence level by the Student's $t$ test.

southward shift of the anomalous cyclonic circulation shown in Fig. 8a. Such asymmetric atmospheric responses also partly explain the significantly increased AAC difference from July to August between 1998 and 

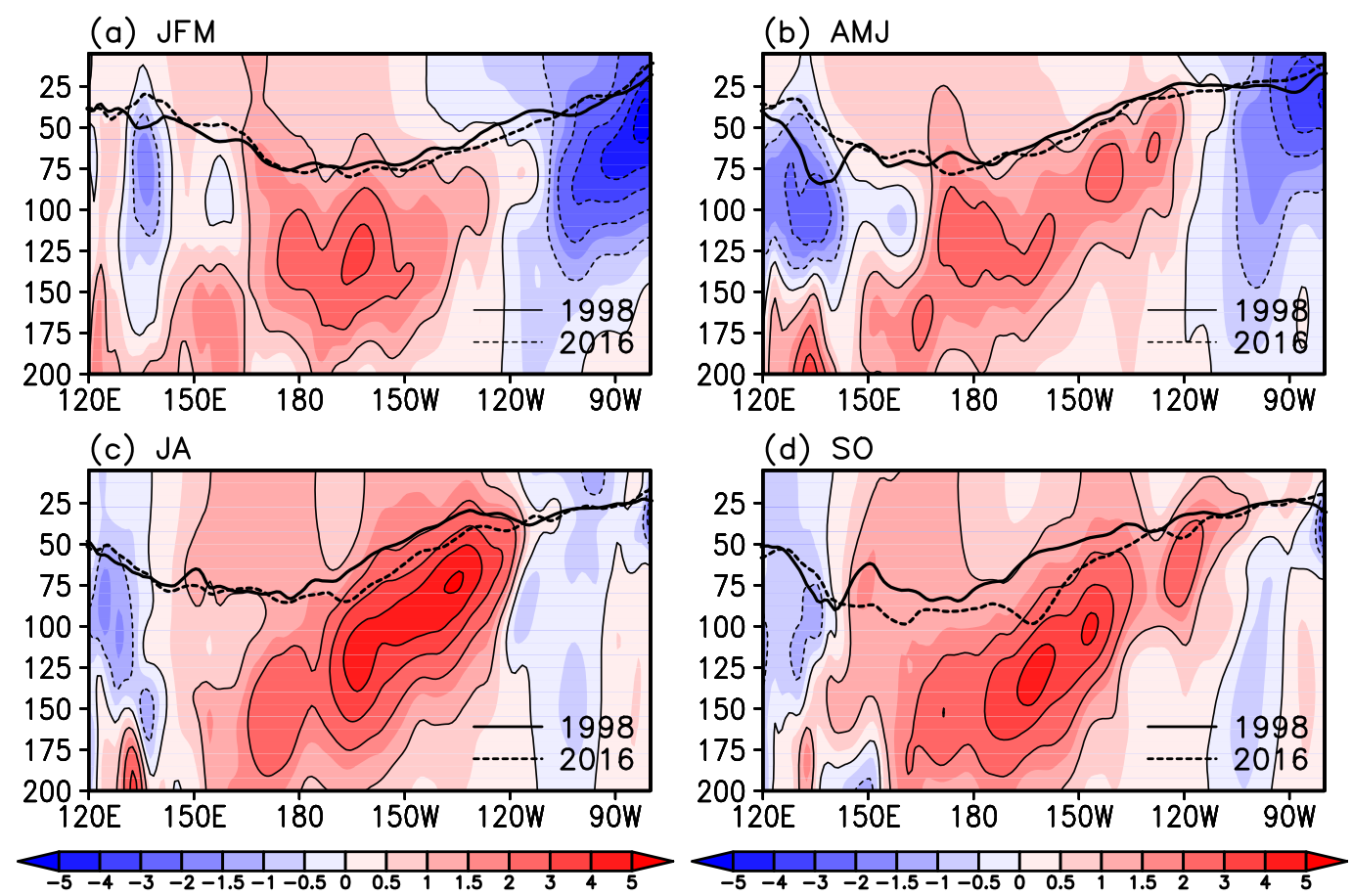

FIG. 9. Longitude-depth cross sections of the differences in the mean seawater temperature (SWT; $\left.{ }^{\circ} \mathrm{C}\right)$ from January to October along the equator $\left(5^{\circ} \mathrm{S}-5^{\circ} \mathrm{N}\right)$ between 2016 and 1998: (a) JFM (b) AMJ, (c) JA, and (d) SO. Thick black curves show the mean mixed layer depth in 1998 (solid) and 2016 (dashed).

2016 in Fig. 5c, although the PMM difference does not show much change from July to August in Fig. 5b.

The above analysis further confirms that the circulation anomalies over the WNP during July-August in 2016 were very similar to the large-scale dynamical and thermodynamic response over the WNP to the positive PMM phase. This thus demonstrates that the positivephase PMM played a dominant role in modulating TC genesis and tracks over the WNP in July-August in 2016.

\section{c. Combined effects of equatorial western Pacific warming and the weak La Niña during September-October}

As indicated in section $4 \mathrm{a}$, the La Niña event was considerably weak in the 2016 typhoon season, while the positive SSTA in the equatorial western Pacific (EWP) intensified gradually and slightly extended eastward, different from the case in 1998 (Fig. 4). Since both ENSO and SSTA in the western Pacific warm pool region have been found to be two important factors modulating WNP TC activity [see the review by Zhan et al. (2012)], we can hypothesize that their combined effect could contribute to active TC activity in September-October of 2016. To verify this hypothesis, we first examined the evolution of seawater temperature (SWT) in the equatorial region. Figure 9 compares the differences in the mean SWT along the equator $\left(5^{\circ} \mathrm{S}-\right.$ $5^{\circ} \mathrm{N}$ ) averaged, respectively, during January-March (JFM), April-June (AMJ), July-August (JA), and September-October (SO) between 2016 and 1998, together with their corresponding mixed layer depths. Overall the SWT in most of the equatorial eastern Pacific was warmer in 2016 than in 1998 and characterized by a deeper mixed layer and an eastward expansion, with larger differences in the typhoon season. This reflects a weaker La Niña signal in 2016 than in 1998. The differences in the EWP between the two years exhibited different patterns east and west of $135^{\circ} \mathrm{E}$ following the transition from the El Niño event to the La Niña event. To the west of $135^{\circ} \mathrm{E}$, the positive difference in SWT between 2016 and 1998 decayed gradually in JFM and turned to the negative difference in the typhoon season, whereas to the east of $135^{\circ} \mathrm{E}$ the positive SWT difference between the two years increased from JFM to SO. Meanwhile, the mixed layer deepened gradually from shallower in JFM to deeper in SO in 2016 than in 1998. These differences favored the SST warming in the EWP in 2016, suggesting that the positive SSTA in the EWP originated from the 2015/16 El Niño event and was maintained and even intensified in SO following the weak La Niña event in 2016. Moreover, $\mathrm{Wu}$ et al. (2014) suggested that the tropical western 

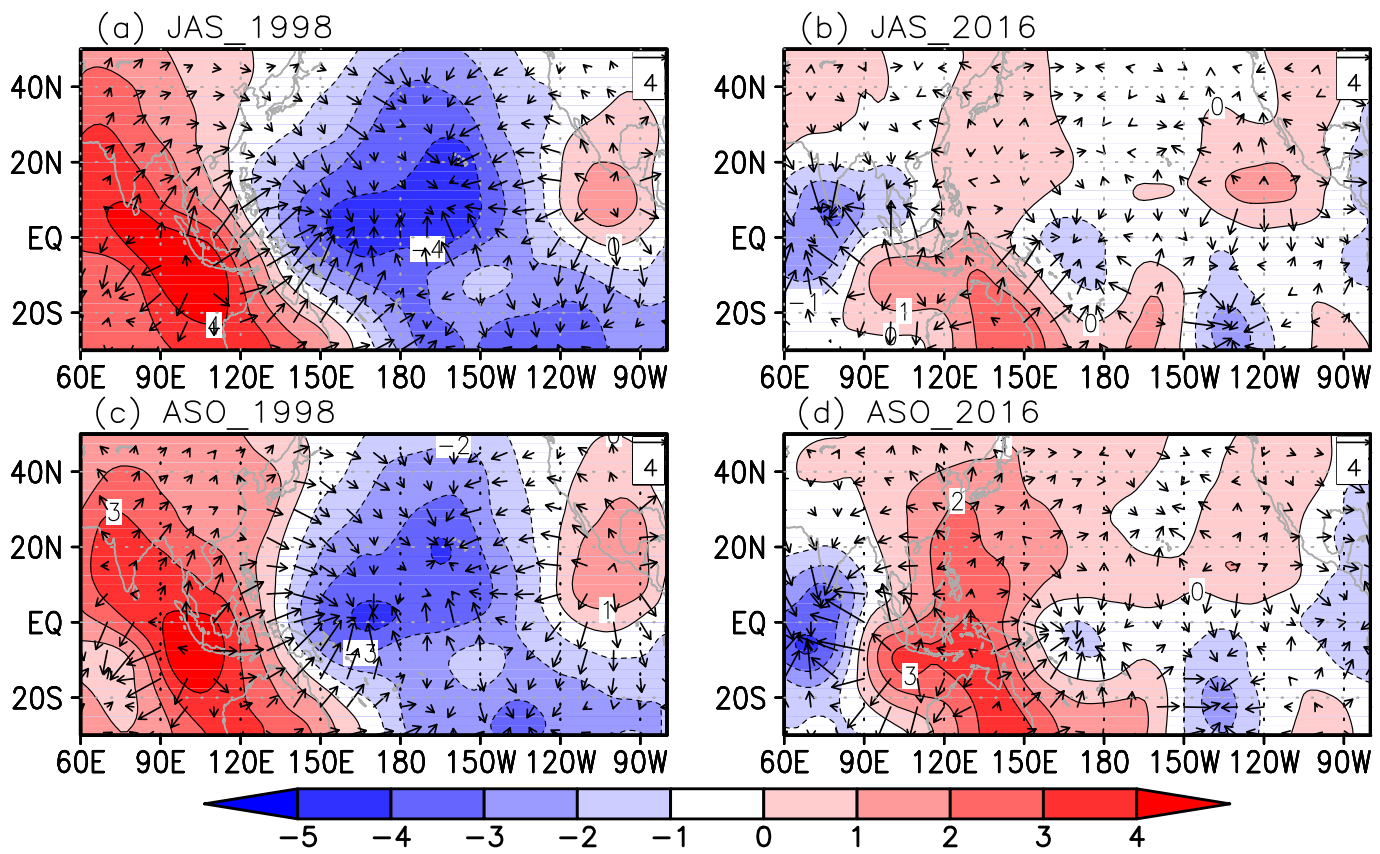

FIG. 10. Seasonal mean 200-hPa divergent wind (vectors) and velocity potential (color shaded; $10^{6} \mathrm{~m}^{2} \mathrm{~s}^{-1}$ ) anomalies for (a),(b) JAS and (c),(d) ASO in (left) 1998 and (right) 2016. The legend at the upper-right corner of the figure indicates a reference vector magnitude.

Pacific warming is likely a response to the atmospheric change. In August 2016, the low-level wind pattern (Fig. 4) acted to pile up warm water in the upper ocean mixed layer. At the same time, the negative precipitation anomalies over the eastern portion of the equatorial western Pacific (Fig. 7) helped increase the downward shortwave radiation there. These could also contribute to the prominent warming in the EWP in SO of 2016.

We then examined the seasonal mean $200-\mathrm{hPa}$ divergent wind and velocity potential anomalies for JulySeptember (JAS) and August-October (ASO) in 1998 and 2016, respectively, as shown in Fig. 10. In 1998, strong upper-level convergence anomalies covered a large area in the tropical and subtropical regions extending from $120^{\circ} \mathrm{E}$ to $120^{\circ} \mathrm{W}$, corresponding to the strong La Niña event. Strong upper-level divergence anomalies occurred over the east Indian Ocean and the SCS and weak upperlevel divergence anomalies were located over the region off the west coast of North America. Consequently, the anomalous subsidence prevailed over most of the WNP and suppressed TC genesis in the 1998 typhoon season. The upper-level anomalous divergence pattern in 2016 differed greatly from that in 1998. The upper-level convergence anomalies were considerably weak over the Pacific, consistent with the weak La Niña event. However, a region with much stronger upper-level convergence anomalies occurred over the Indian Ocean and the western part of the SCS, most likely forced by deep convection over the WNP where positive SSTAs occurred (Fig. 4) with strong upper-level divergence anomalies. The upper-level divergence anomalies and the associated upward motion favored TC genesis over the WNP in the typhoon season in 2016, which was in opposite to the case in 1998.

To further analyze the differences in the thermodynamic and dynamical factors controlling TC geneses between 1998 and 2016, we calculated the genesis potential index (GPI) and the contribution of each individual factor. The GPI modified by Murakami et al. (2011) is used here, which includes the midlevel vertical $p$ velocity as an extra factor. The formula of the modified GPI is given as

$$
\mathrm{GPI}=\left|10^{5} \eta\right|^{3 / 2}\left(\frac{\mathrm{RH}}{50}\right)^{3}\left(\frac{V_{\mathrm{pot}}}{70}\right)^{3}\left(1+0.1 V_{s}\right)^{-2}\left(\frac{-\omega+0.1}{0.1}\right),
$$

where $\eta$ is the $850-\mathrm{hPa}$ absolute vorticity $\left(\mathrm{s}^{-1}\right), \mathrm{RH}$ is the 700 -hPa relative humidity (\%), $V_{\text {pot }}$ is the potential intensity $\left(\mathrm{m} \mathrm{s}^{-1}\right), V_{s}$ is the magnitude of VWS $\left(\mathrm{m} \mathrm{s}^{-1}\right)$ between 200 and $850 \mathrm{hPa}$, and $\omega$ is the $500-\mathrm{hPa}$ vertical $p$ velocity $\left(\mathrm{Pa} \mathrm{s}^{-1}\right)$. The individual roles of the five variables were calculated following Camargo et al. (2007b). We calculated the GPI using the climatological mean of 

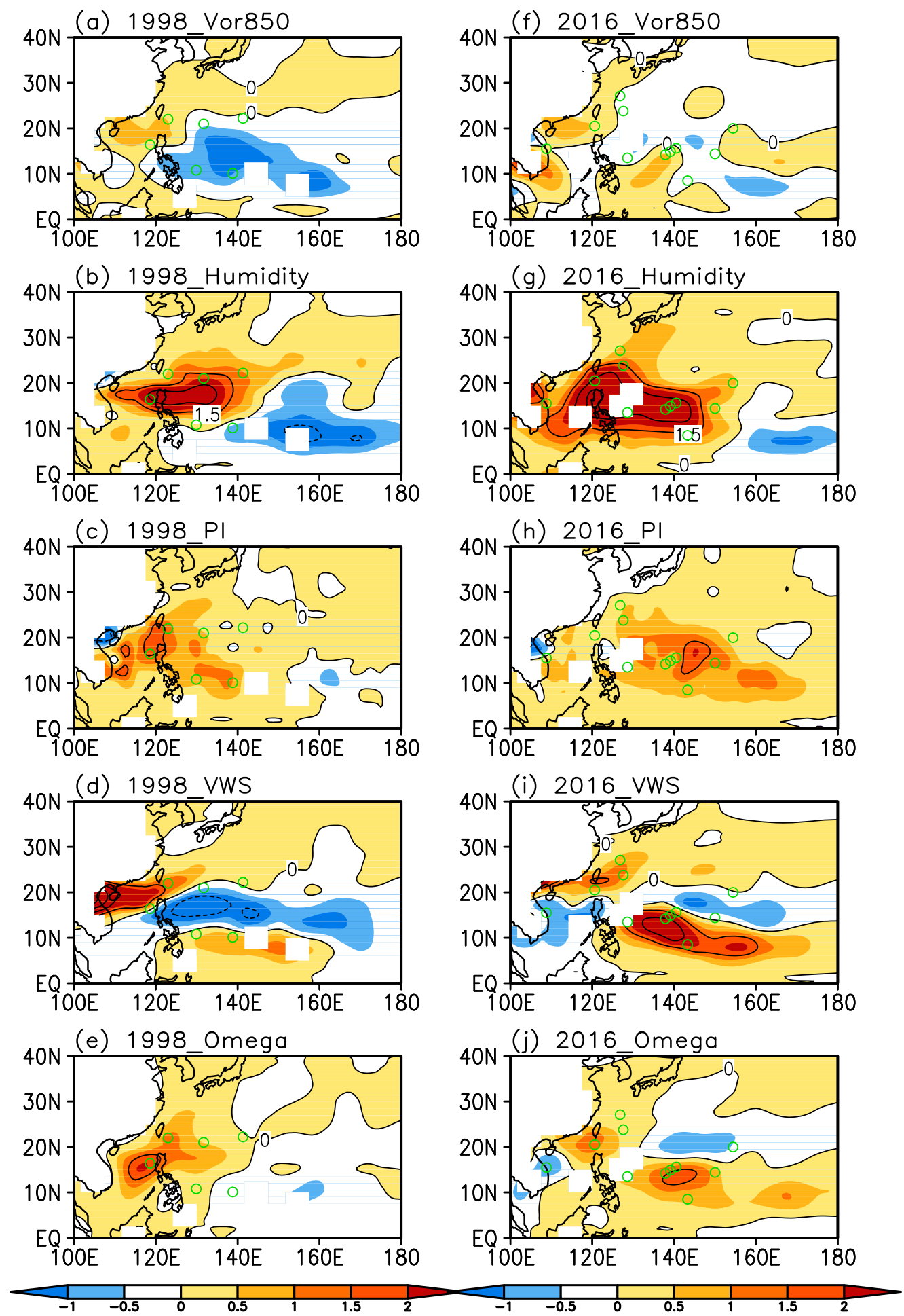

FIG. 11. Relative contributions of (a) 850-hPa absolute vorticity (VOR), (b) midlevel relative humidity (RH), (c) potential intensity (PI), (d) vertical wind shear (VWS), and (e) vertical velocity ( $\omega$ ) to the total GPI during September-October 1998. (f)-(j) As in (a)-(e), but for 2016. Green circles in the panels are TC genesis locations in the corresponding months. The white squares in the panels indicate the areas where the data are missing. 
four of the five variables while keeping the fifth variable as the actual value in 1998 or 2016 . The difference between the above GPI with varying variable and the climatological mean GPI was considered as the relative contribution of this variable.

Figure 11 shows the relative contributions of the five variables to the total GPI anomalies over the WNP in SO of 1998 and 2016, respectively. Compared the two years, the less active TC activity in SO of 1998 (namely negative GPI anomalies) was mainly contributed by the anomalous low-level anticyclonic vorticity (Fig. 11a), midlevel humidity in the southeastern quadrant of the WNP (Fig. 11b), and VWS in the main TC genesis region (Fig. 11d), with negligible contributions by both PI (Fig. 11c) and midlevel vertical $p$ velocity (Fig. 11e). The active TC activity in SO of 2016 (positive GPI anomalies) was contributed by all five variables with the least important factor being the low-level relative vorticity (Fig. 11f) and with the most important factor being the midlevel relative humidity (Fig. 11g). The negative contribution by low-level vorticity in 1998 was largely related to the low-level AAC associated with the equatorial anomalous easterlies while that by midlevel humidity east of $130^{\circ} \mathrm{E}$ was related to cold SSTAs over the southeastern WNP. Both effects were tied to the strong La Niña event. The positive contributions by PI, vertical motion, and midlevel humidity in 2016 could be closely related to the local SSTA and the anomalous confluence zone, while the positive contribution by VWS might be due to the anomalous cyclonic circulation over the WNP. All of these in 2016 were closely related to the EWP warming and the weak La Niña event. Therefore, we can conclude that the active TC activity in SO of 2016 resulted mainly from a combined effect of the EWP warming and the weak La Niña event.

Finally, to provide further evidence to support the above analyses, we examined cases with similar SST patterns since 1980. Since the warming in the EWP was mainly located west of $130^{\circ} \mathrm{E}$ in 1998 and east of $135^{\circ} \mathrm{E}$ in 2016, two SSTA indices were defined based on Fig. 4. Here the western western Pacific (WWP) and EWP SSTA indices representing warming patterns in 1998 and 2016 were defined as SSTAs averaged in the area of $5^{\circ} \mathrm{S}-5^{\circ} \mathrm{N}, 100^{\circ}-130^{\circ} \mathrm{E}$ and in the area of $5^{\circ} \mathrm{S}-5^{\circ} \mathrm{N}, 135^{\circ}-$ $160^{\circ} \mathrm{E}$, respectively. Figure 12 shows the interannual variations of the Niño-3.4 index, WWP SSTA index, and the EWP SSTA index averaged in SO during 1980-2016. We can see that 1988, 1998, and 2010 can be considered as three strong La Niña events following the El Niño events with a Niño-3.4 index below $-1.0^{\circ} \mathrm{C}$ (Fig. 12a), while the La Niña events following the El Niño events were weak in 1983, 1995, 2007 and 2016 with a Niño-3.4 index between $-0.5^{\circ}$ and $-1.0^{\circ} \mathrm{C}$ (Fig. 12b). In the three

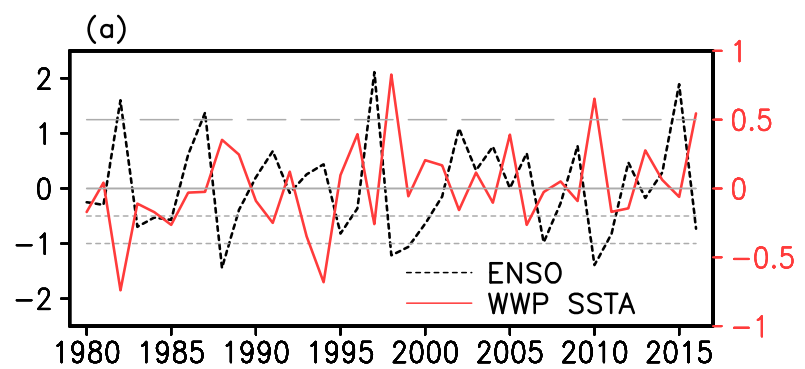

(b)

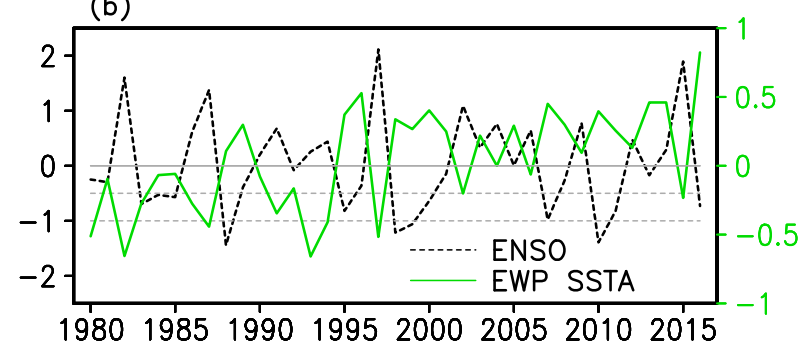

FIG. 12. Interannual variations of (a) the ENSO index (black dashes) and the WWP SSTA index (red solid) and (b) the ENSO index (black dashes) and the EWP SSTA index (green solid) averaged in September-October during 1980-2016.

strong La Niña events, although all were positive, the WWP SSTAs in 1998 and 2010 were extremely large with the index over $0.5^{\circ} \mathrm{C}$, whereas the warming over the WWP was relatively small and comparable to that over the eastern EWP in 1988. Therefore, 2010 was considered as a case similar to 1998. For the four weak La Niña events, the EWP SSTA index was positive and considerably large in 1995, 2007, and 2016 whereas the EWP SSTA index was negative in 1983. As a result, the SSTA patterns in both 1995 and 2007 had better similarity to that in 2016. Thus, these three cases were selected to confirm our results above.

Figure 13 shows the mean SST and 850-hPa wind anomalies averaged during SO in 1995, 2007, and 2010, respectively, together with the corresponding TC genesis locations. For better comparison, the same fields in 1998 and 2016 were also given in Fig. 13. The SSTA pattern in SO of 2010 was very similar to that in 1998, which exhibited a strong La Niña event and strong warming from the east Indian Ocean to the western Pacific, followed by strong anomalous easterlies penetrating from the WNP to the SCS. This was unfavorable for TC genesis and only six TCs formed over the WNP in SO of 2010, the same as in 1998. For the weak La Niña cases, both 1995 and 2007 showed SSTA patterns very similar to that in 2016, although the EWP SSTAs were much smaller in 1995 and 2007 than in 2016. The negative SSTA in the equatorial Pacific was smaller and limited to the east of around $165^{\circ} \mathrm{E}$ and the positive SSTA was observed in the EWP. Correspondingly, in 

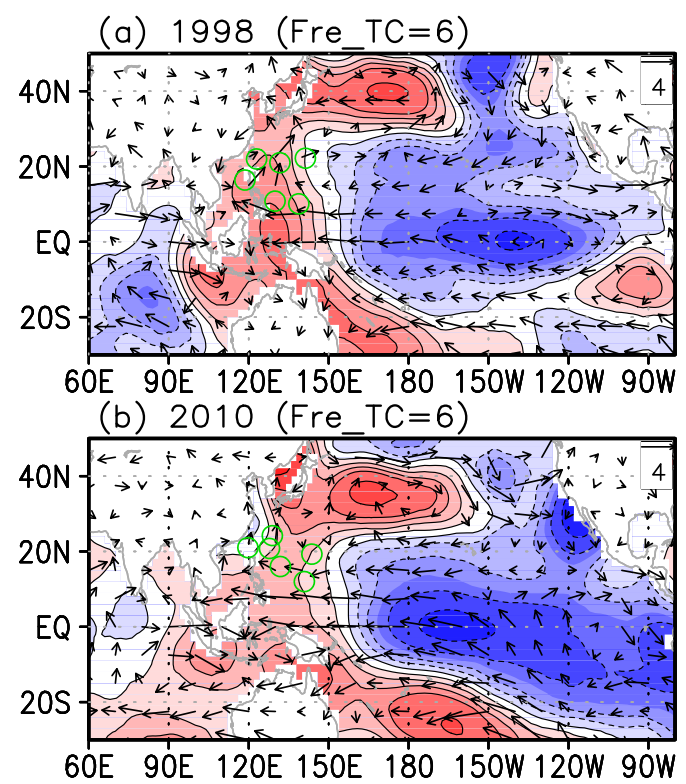
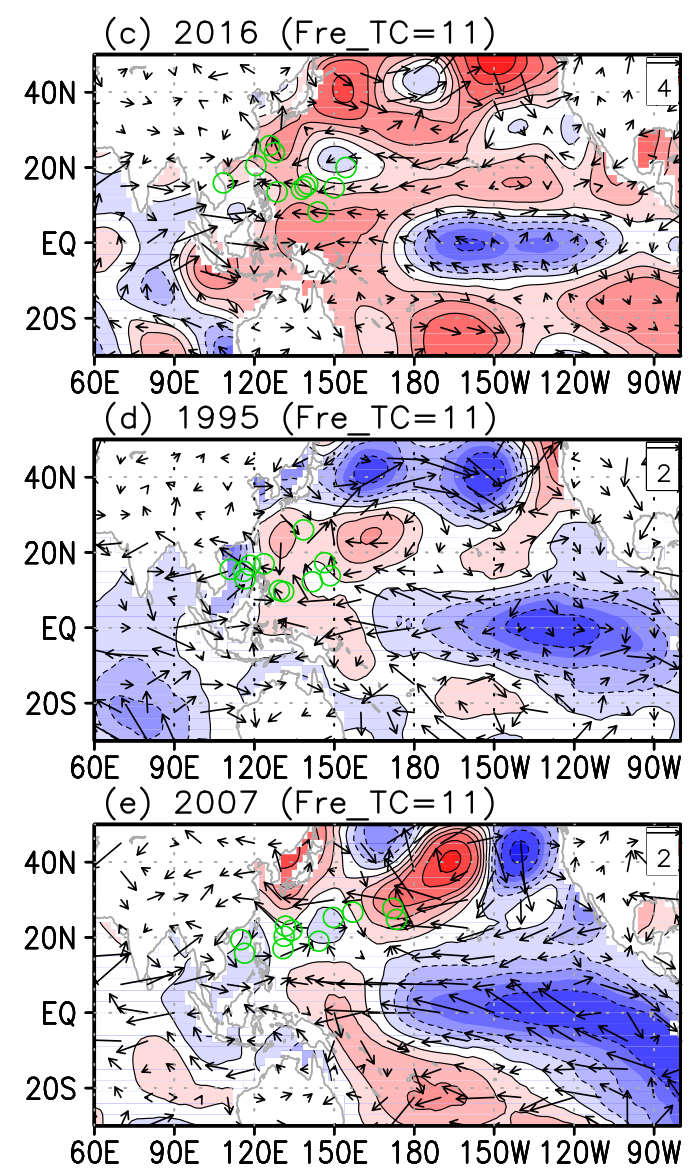

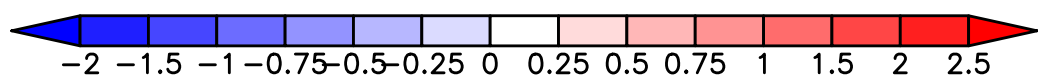

FIG. 13. Seasonal mean SSTA (color shaded; ${ }^{\circ} \mathrm{C}$ ) and $850-\mathrm{hPa}$ wind (vectors; $\mathrm{m} \mathrm{s}^{-1}$ ) anomalies during September-October of (a) 1998, (b) 2010, (c) 2016, (d) 1995, and (d) 2007. The legend at the upper-right corner of the figure indicates a reference vector magnitude. The green circles indicate TC genesis positions.

both 1995 and 2007, anomalous westerlies met anomalous easterlies to the east of Philippines and anomalous cyclonic circulation occurred to the northwest in response to the warm SSTA in the EWP. This anomalous circulation pattern was very similar to that in 2016 and resulted in 11 TCs over the WNP during SO in both years, the same as in 2016. This further confirms that the combined effect of the EWP warming and the weak La Niña predominantly contributed to the active TC activity during SO in 2016.

\section{Conclusions and discussion}

In this study, we have examined salient differences in TC activities over the WNP between 1998 and 2016, namely in the decaying years of two super El Niño events, respectively, in 1997 and 2015. Consistent with the previously documented relationship between ENSO and TC activity over the WNP, the TC activity in 1998 was extremely inactive. No TC formed during the preseason and only 10 TCs formed during the typhoon season, making the year a record low. However, although no TC formed during the preseason, similar to that in 1998, above-normal named and intense TCs were observed during the typhoon season in 2016.

Consistent with previous studies, the inactive preseason in these two years can be explained dynamically in relation to the strong AAC associated with the super El Niño events. However, the salient differences in TC activity between the 1998 and 2016 typhoon seasons were attributed to the different SSTA patterns and the associated anomalous circulations. The strong AAC in 1998 was maintained by the strong La Niña event and the warming in the Indian Ocean, thus suppressing TC activity through the whole typhoon season. However, in the 2016 typhoon season the AAC disappeared and the main TC genesis region over the WNP was covered by 
an anomalous cyclonic circulation during July-August. Further analysis shows that the extremely positive PMM phase played an important role in triggering such an anomalous cyclonic circulation and reducing large-scale vertical wind shear over the WNP, and thus was favorable for more TC geneses over the WNP during JulyAugust in 2016. The different behaviors in TC activity in SO between 1998 and 2016 can be explained by the different SSTA patterns in the EWP and the ECEP. The cold SSTA associated with the weak La Niña event in 2016 was limited to the east of the date line and large warming occurred over the EWP. The combined effect of the weak La Niña event and the warm EWP resulted in a convergence area of anomalous westerly and easterly, and thus enhanced the monsoon confluence zone around $140^{\circ} \mathrm{E}$ and convection over the western EWP. Convective heating further triggered an anomalous cyclonic circulation, anomalous upward vertical motions, and an anomalous wet belt in the main TC genesis region to the northwest, favorable for more TC geneses over the WNP.

Our results have important implications for the relationship between ENSO and TC activity over the WNP. Previous studies have suggested an inactive TC season over the WNP in the decaying year of a strong El Niño event. However, it was not the case in 2016, indicating that whether the TC season would be active or inactive in the decaying year of a strong El Niño event is determined greatly by the strength of the developing La Niña event following the strong El Niño event and the SSTA over the EWP. Previous studies have also shown no significant correlation between the annual TC frequency over the WNP and the Niño-3.4 index. Our results strongly suggest that this could be due to the fact that TC activity over the WNP is affected not only by SSTAs in the Niño-3.4 region, but also by the SSTA pattern in the tropical Pacific and even by SSTAs in other ocean basins.

An interesting issue arises as to how the unique SSTA pattern in 2016 formed. As mentioned above, unlike the traditional SSTA patterns associated with La Niña events, the outer ring of the negative SSTAs over the equatorial central and eastern Pacific was characterized by a large warming in the 2016 typhoon season. Such an SSTA pattern is very similar to the SSTA pattern during the global warming hiatus period (Kosaka and Xie 2013). A plausible hypothesis is that the unique SSTA pattern in 2016 is attributed to the effect of climate change. Many previous studies have shown that climate change plays an important role in TC activities over the WNP (e.g., Kossin et al. 2014; Huang et al. 2015; Lin and Chan 2015). In this sense, the salient difference in TC activity between the 1998 and 2016 typhoon seasons might also be partially associated (a) 1998

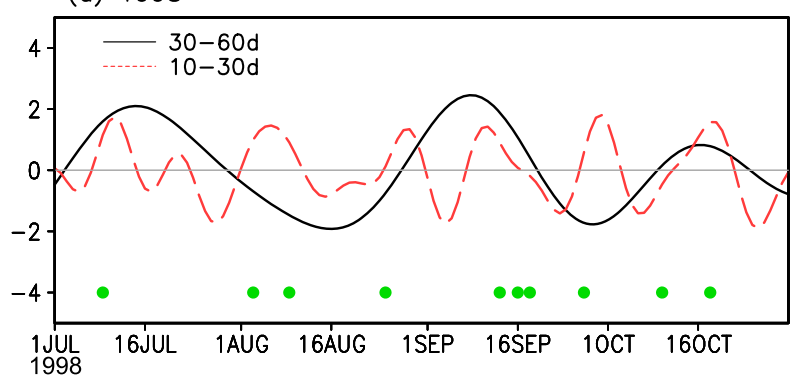

(b) 2016

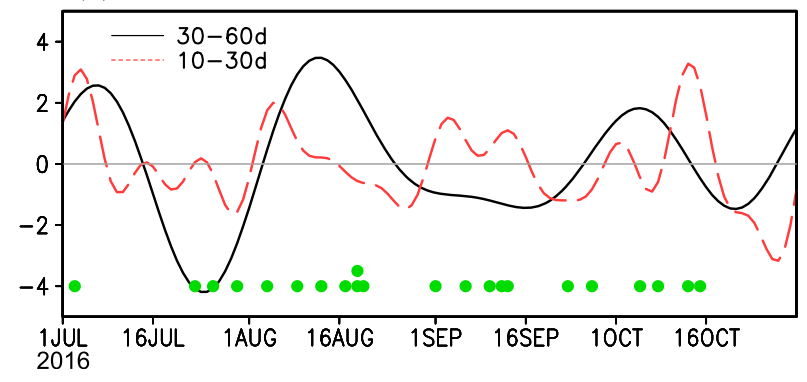

FIG. 14. Time series of the 30-60-day (black solid) and 10-30-day (red dashes) bandpass-filtered $850-\mathrm{hPa}$ zonal wind $\left(\mathrm{m} \mathrm{s}^{-1}\right)$ averaged in in the area of $0^{\circ}-20^{\circ} \mathrm{N}, 120^{\circ}-150^{\circ} \mathrm{E}$ in (a) 1998 and (b) 2016. The green dots indicate the time of each TC genesis.

with climate change, which deserves further study in the future.

Note that in this study we have only examined the impacts of SSTAs in the tropical Pacific on TC activity over the WNP, focusing on two extreme years. Actually, as mentioned in the introduction, there could be other factors that can significantly modulate TC activity in the basin. For example, the summer monsoon activity over the Bay of Bengal and the SCS might also play a role in TC genesis during August 2016. As shown in Fig. 4, the $850-\mathrm{hPa}$ zonal wind anomalies over the Bay of Bengal and the SCS changed from easterly to westerly from July to August, which could contribute to the stronger cyclonic circulation anomaly over the WNP. In this sense, the difference in summer monsoon activity over the Bay of Bengal and the SCS could also be a factor contributing to the contrast in TC genesis in August over the WNP between 1998 and 2016. However, the location of the anomalous circulation over the WNP in August 2016 shifted northward and eastward, suggesting that the influence of summer monsoon might be secondary compared to the positive PMM. Another possible effect is the intraseasonal oscillation (ISO). In general, cyclogenesis is often preferentially enhanced (suppressed) during the active (inactive) phase of the ISO over the Indian Ocean and the WNP (Liebmann et al. 1994; Kim et al. 2008). We conducted a spectrum analysis on the $850-\mathrm{hPa}$ zonal wind averaged in the area of $120^{\circ}-150^{\circ} \mathrm{E}$, 
$0^{\circ}-20^{\circ} \mathrm{N}$ and found strong signals on both 10-30-day [quasi-biweekly oscillation (QBWO)] and 30-60-day [Madden-Julian oscillation (MJO)] time scales in 2016. Figure 14 shows the time series of the 30-60-day and 10-30-day bandpass-filtered $850-\mathrm{hPa}$ zonal wind in 1998 and 2016, together with times of TC geneses in green dots. It can be seen that the enhanced cyclogeneses during July-August of 2016 seemed not to be related to the active phases of the ISO, whereas the TC activity in SO was more closely associated with the ISO. The QBWO likely contributed to TC activity in September, whereas the QBWO and the MJO contributed equally TC activity in October. We also examined the time-longitude cross section of the OLR and 850-hPa zonal wind anomalies (not shown) and found that TCs generally formed at the initial times of anomalous westerly appearance in the convective phase of the ISO. This means that the ISO in SO of 2016 was locally forced over the EWP where the SSTs were quite warm.

Finally, we should point out that the results obtained in this study have been based on observational analyses. The effects of individual SSTAs and their relative contributions to TC activity in these two extreme years have not been examined, which could be better explored in a future study using a high-resolution coupled climate model.

Acknowledgments. The authors are grateful to Prof. $\mathrm{Tim} \mathrm{Li}$ and three anonymous reviewers for their helpful comments on the manuscript. This study has been supported by the National Natural Science Foundation of China (Grants 41375093, 41475082, and 41575052). Ruifen Zhan was supported in part by JAMSTEC through its sponsorship of the International Pacific Research Center (IPRC) in the School of Ocean and Earth Science and Technology (SOEST) at the University of Hawaii at Manoa. Additional support has been provided by the Typhoon Scientific and Technological Innovation Group of Shanghai Meteorological Service. The CMA best-track TC dataset was downloaded from http://tcdata.typhoon. org.cn/. The monthly ERSST.v4 analyses were downloaded from https://www.esrl.noaa.gov/psd/data/gridded/ data.noaa.ersst.v4.html. The NCEP-NCAR reanalysis data were downloaded from https://www.esrl.noaa.gov/psd /data/gridded/data.ncep.reanalysis.html. The CMAP data were downloaded from https://www.esrl.noaa.gov/psd/ data/gridded/data.cmap.html. The SWT data were downloaded from https://www.esrl.noaa.gov/psd/.

\section{REFERENCES}

Bell, G. D., and Coauthors, 2000: Climate assessment for 1999. Bull. Amer. Meteor. Soc., 81 (6), S1-S50, doi:10.1175/ 1520-0477(2000)81[s1:CAF]2.0.CO;2.
Camargo, S. J., and A. H. Sobel, 2005: Western North Pacific tropical cyclone intensity and ENSO. J. Climate, 18, 29963006, doi:10.1175/JCLI3457.1.

— A. W. Robertson, S. J. Gaffney, P. Smyth, and M. Ghil, 2007a: Cluster analysis of typhoon tracks. Part II: Large-scale circulation and ENSO. J. Climate, 20, 3654-3676, doi:10.1175/ JCLI4203.1.

$\longrightarrow$, K. A. Emanuel, and A. H. Sobel, 2007b: Use of a genesis potential index to diagnose ENSO effects on tropical cyclone genesis. J. Climate, 20, 4819-4834, doi:10.1175/JCLI4282.1.

Chan, J. C. L., 2000: Tropical cyclone activity over the western North Pacific associated with El Niño and La Niña events. J. Climate, 13, 2960-2972, doi:10.1175/ 1520-0442(2000)013\%3C2960:TCAOTW\%3E2.0.CO;2.

- 2007: Interannual variations of intense typhoon activity. Tellus, 59A, 455-460, doi:10.1111/j.1600-0870.2007.00241.x.

Chen, G. H., and R. H. Huang, 2008: Influence of monsoon over the warm pool on interannual variation of tropical cyclone activity over the western North Pacific. Adv. Atmos. Sci., 25, 319-328, doi:10.1007/s00376-008-0319-7.

Chen, T. C., S. Y. Wang, and M. C. Yen, 2006: Interannual variation of the tropical cyclone activity over the western North Pacific. J. Climate, 19, 5709-5720, doi:10.1175/JCLI3934.1.

Chen, Z., Z. Wen, R. Wu, X. Lin, and J. Wang, 2016: Relative importance of tropical SST anomalies in maintaining the western North Pacific anomalous anticyclone during El Niño to La Niña transition years. Climate Dyn., 46, 1027-1041, doi:10.1007/s00382-015-2630-1.

Chia, H. H., and C. F. Ropelewski, 2002: The interannual variability in the genesis location of tropical cyclones in the northwest Pacific. J. Climate, 15, 2934-2944, doi:10.1175/ 1520-0442(2002)015<2934:TIVITG > 2.0.CO;2.

Chiang, J. C. H., and D. J. Vimont, 2004: Analogous Pacific and Atlantic meridional modes of tropical atmosphere-ocean variability. J. Climate, 17, 4143-4158, doi:10.1175/JCLI4953.1.

Du, Y., L. Yang, and S.-P. Xie, 2011: Tropical Indian Ocean influence on northwest Pacific tropical cyclones in summer following strong El Niño. J. Climate, 24, 315-322, doi:10.1175/ 2010JCLI3890.1.

Emanuel, K. A., 2005: Increasing destructiveness of tropical cyclones over the past 30 years. Nature, 436, 686-688, doi:10.1038/nature03906.

Fan, L., S. Shin, Q. Y. Liu, and Z. Y. Liu, 2013: Relative importance of tropical SST anomalies in forcing East Asian summer monsoon circulation. Geophys. Res. Lett., 40, 2471-2477, doi:10.1002/grl.50494.

Fudeyasu, H., S. Iizuka, and T. Matsuura, 2006: Impact of ENSO on landfall characteristics of tropical cyclones over the western North Pacific during the summer monsoon season. Geophys. Res. Lett., 33, L21815, doi:10.1029/2006GL027449.

Gill, A. E., 1980: Some simple solutions for heat-induced tropical circulation. Quart. J. Roy. Meteor. Soc., 106, 447-462, doi:10.1002/qj.49710644905.

Ha, Y., and Z. Zhong, 2013: Contrast of tropical cyclone frequency in the western North Pacific between two types of La Niña events. Sci. China: Earth Sci., 56, 397-407, doi:10.1007/ s11430-012-4475-3.

Huang, P., I.-I. Lin, C. Chou, and R. H. Huang, 2015: Change in ocean subsurface environment to suppress tropical cyclone intensification under global warming. Nat. Commun., 6, 7188, doi:10.1038/ncomms8188.

Huo, L. W., P. W. Guo, S. N. Hameed, and D. C. Jin, 2015: The role of tropical Atlantic SST anomalies in modulating western 
North Pacific tropical cyclone genesis. Geophys. Res. Lett., 42 , 2378-2384, doi:10.1002/2015GL063184.

Iizuka, S., and T. Matsuura, 2008: ENSO and western North Pacific tropical cyclone activity simulated in a CGCM. Climate Dyn., 30, 815-830, doi:10.1007/s00382-007-0326-x.

Ji, M., A. Leetmaa, and J. Derber, 1995: An ocean analysis system for seasonal to interannual climate studies. Mon. Wea. Rev., 123, 460-481, doi:10.1175/1520-0493(1995)123<0460: AOASFS $>2.0 . \mathrm{CO} ; 2$.

Kalnay, E., and Coauthors, 1996: The NCEP/NCAR 40-Year Reanalysis Project. Bull. Amer. Meteor. Soc., 77, 437-471, doi:10.1175/1520-0477(1996)077<0437:TNYRP>2.0.CO;2.

Kim, J. H., C. H. Ho, H. S. Kim, C. H. Sui, and S. K. Park, 2008: Systematic variation of summertime tropical cyclone activity in the western North Pacific in relation to the Madden-Julian oscillation. J. Climate, 21,1171-1191, doi:10.1175/2007JCLI1493.1.

Kosaka, Y., and S.-P. Xie, 2013: Recent global-warming hiatus tied to equatorial Pacific surface cooling. Nature, 501, 403-407, doi:10.1038/nature12534.

Kossin, J. P., K. A. Emanuel, and G. A. Vecchi, 2014: The poleward migration of the location of tropical cyclone maximum intensity. Nature, 509, 349-352, doi:10.1038/nature13278.

Lander, M., 1994: An exploratory analysis of the relationship between tropical storm formation in the western North Pacific and ENSO. Mon. Wea. Rev., 122, 636-651, doi:10.1175/ 1520-0493(1994)122<0636:AEAOTR > 2.0.CO;2.

Liebmann, B., H. H. Hendon, and J. D. Glick, 1994: The relationship between tropical cyclones of the western Pacific and Indian Oceans and the Madden-Julian oscillation. J. Meteor. Soc. Japan, 72, 401-412, doi:10.2151/jmsj1965.72.3_401.

Lin, I.-I., and J. C. L. Chan, 2015: Recent decrease in typhoon destructive potential and global warming implications. Nat. Commun., 6, 7182, doi:10.1038/ncomms8182.

Murakami, H., B. Wang, and A. Kitoh, 2011: Future change of western North Pacific typhoons: Projections by a $20-\mathrm{km}-\mathrm{mesh}$ global atmospheric model. J. Climate, 24, 1154-1169, doi:10.1175/2010JCLI3723.1.

Smith, T. M., and R. W. Reynolds, 2004: Improved extended reconstruction of SST (1854-1997). J. Climate, 17, 2466-2477, doi:10.1175/1520-0442(2004)017\%3C2466:IEROS\%3E2.0.CO;2.

Tao, L., L. Wu, Y. Wang, and J. Yang, 2012: Influences of tropical Indian Ocean warming and ENSO on tropical cyclone activity over the western North Pacific. J. Meteor. Soc. Japan, 90, 127 144, doi:10.2151/jmsj.2012-107.

Wang, B., and J. C. L. Chan, 2002: How strong ENSO events affect tropical cyclone activity over the western North Pacific J. Climate, 15, 1643-1658, doi:10.1175/1520-0442(2002)015<1643: HSEEAT $>2.0 . \mathrm{CO} ; 2$.

— R. G. Wu, and T. Li, 2003: Atmosphere-warm ocean interaction and its impacts on Asian-Australian monsoon variation. J. Climate, 16, 1195-1211, doi:10.1175/1520-0442(2003)16<1195: AOIAII $>2.0 . \mathrm{CO} ; 2$.

- J. Liu, H. J. Kim, P. J. Webster, S. Y. Yim, and B. Xiang, 2013: Northern Hemisphere summer monsoon intensified by mega-El Niño/Southern Oscillation and Atlantic multidecadal oscillation. Proc. Natl. Acad. Sci. USA, 110, 5347-5352, doi:10.1073/pnas.1219405110.

Wu, B., T. Li, and T. Zhou, 2010: Relative contributions of the Indian Ocean and local SST anomalies to the maintenance of the western North Pacific anomalous anticyclone during El Niño decaying summer. J. Climate, 23, 2974-2986, doi:10.1175/ 2010JCLI3300.1.
Wu, M. C., W. L. Chang, and W. M. Leung, 2004: Impacts of El Niño-Southern Oscillation events on tropical cyclone landfalling activity in the western North Pacific. J. Climate, 17, 1419-1428, doi:10.1175/1520-0442(2004)017\%3C1419: IOENOE\%3E2.0.CO;2.

Wu, R., S. Yang, Z. Wen, G. Huang, and K. M. Hu, 2012: Interdecadal change in the relationship of southern China summer rainfall with tropical Indo-Pacific SST. Theor. Appl. Climatol., 108, 119-133, doi:10.1007/s00704-011-0519-4.

—, G. Huang, Z. C. Du, and K. M. Hu, 2014: Cross-season relation of the South China Sea precipitation variability between winter and summer. Climate Dyn., 43, 193-207, doi:10.1007/ s00382-013-1820-y.

Xie, P., and P. A. Arkin, 1997: Global precipitation: A 17-year monthly analysis based on gauge observation, satellite estimates, and numerical model outputs. Bull. Amer. Meteor. Soc., 78, 2539-2558, doi:10.1175/1520-0477(1997)078<2539: GPAYMA $>2.0 . \mathrm{CO} ; 2$.

Xie, S.-P., K. Hu, J. Hafner, H. Tokinaga, Y. Du, G. Huang, and T. Sampe, 2009: Indian Ocean capacitor effect on Indowestern Pacific climate during the summer following El Niño. J. Climate, 22, 730-747, doi:10.1175/2008JCLI2544.1.

_ , Y. Kosaka, Y. Du, K. M. Hu, J. Chowdary, and G. Huang, 2016: Indo-western Pacific Ocean capacitor and coherent climate anomalies in post-ENSO summer: A review. $A d v$. Atmos. Sci., 33, 411-432, doi:10.1007/s00376-015-5192-6.

Yang, J., Q. Liu, S.-P. Xie, Z. Liu, and L. Wu, 2007: Impact of the Indian Ocean SST basin mode on the Asian summer monsoon. Geophys. Res. Lett., 34, L02708, doi:10.1029/2006GL028571.

Ying, M., W. Zhang, H. Yu, X. Lu, J. Feng, Y. Fan, Y. Zhu, and D. Chen, 2014: An overview of the China Meteorological Administration tropical cyclone database. J. Atmos. Oceanic Technol., 31, 287-301, doi:10.1175/JTECH-D-12-00119.1.

Zhan, R. F., Y. Wang, and X.-T. Lei, 2011a: Contributions of ENSO and east Indian Ocean SSTA to the interannual variability of northwest Pacific tropical cyclone frequency. J. Climate, 24, 509-521, doi:10.1175/2010JCLI3808.1.

, - - and C.-C. Wu, 2011b: Impact of SSTA in east Indian Ocean on the frequency of northwest Pacific tropical cyclones: A regional atmospheric model study. J. Climate, 24, 62276242, doi:10.1175/JCLI-D-10-05014.1.

,-- , and M. Ying, 2012: Seasonal forecasts of tropical cyclone activity over the western North Pacific: A review. Trop. Cyclone Res. Rev., 1, 307-324, doi:10.6057/2012TCRR03.07.

_ - - and M. Wen, 2013: The SST gradient between the southwestern Pacific and the western Pacific warm pool: A new factor controlling the northwestern Pacific tropical cyclone genesis frequency. J. Climate, 26, 2408-2415, doi:10.1175/JCLI-D-12-00798.1.

_ _ _ , and L. Tao, 2014: Intensified impact of east Indian Ocean SST anomaly on tropical cyclone genesis frequency over the western North Pacific. J. Climate, 27, 8724-8739, doi:10.1175/JCLI-D-14-00119.1.

Zhang, W., G. A. Vecchi, H. H. Murakami, G. G. Villarini, and L. Jia, 2016: The Pacific meridional mode and the occurrence of tropical cyclones in the western North Pacific. J. Climate, 29, 381-398, doi:10.1175/JCLI-D-15-0282.1.

- - - G. Villarini, H. Murakami, R. Gudgel, and X. Yang, 2017: Statistical-dynamical seasonal forecast of western North Pacific and East Asia landfalling tropical cyclones using the GFDL FLOR coupled climate model. J. Climate, 30, 22092232, doi:10.1175/JCLI-D-16-0487.1. 